3

\title{
Shear behaviour of non-prismatic steel reinforced concrete beams
}

Dr John J Orr ${ }^{\mathrm{a}, \mathrm{b}}$,Professor Timothy J Ibell ${ }^{\mathrm{a}}$, Dr Antony P Darby ${ }^{\mathrm{a}}$ and Dr Mark Evernden ${ }^{\mathrm{a}}$

${ }^{a}$ Department of Architecture and Civil Engineering, University of Bath, BA2 $7 A Y$.

${ }^{b}$ Corresponding Author: Telephone: +44 (0) 1225385096 email: j.j.orr@bath.ac.uk

\section{Abstract}

Large reductions in embodied carbon can be achieved through the optimisation of concrete structures. Such structures tend to vary in depth along their length, creating new challenges for shear design. To address this challenge, nineteen tests on non-prismatic steel reinforced concrete beams designed using three different approaches were undertaken at the University of Bath. The results show that the assumptions of some design codes can result in unconservative shear design for non-prismatic sections.

Keywords: Shear, shear reinforcement, structural behaviour, non-prismatic beams, optimisation. 


\section{Introduction}

Non-prismatic concrete beams can provide steel and concrete savings when used to replace equivalent strength prismatic elements. In a variable section reinforced concrete beam a portion of the shear force may theoretically be carried by a suitably inclined top or bottom flange, yet such beams have been found to fail prematurely, suggesting codified methods are unable to account for the varying section shapes found in optimised structures. Given that optimised structures tend to be non-prismatic, understanding these failures and providing appropriate guidance for their design is hugely important.

\section{Tapered beams}

\subsection{Shear behaviour}

The derivation of shear stresses through equilibrium considerations of a homogenous uncracked and isotropic beam is relatively straightforward, but the behaviour of a reinforced concrete section is more complex. In a reinforced section, cracks will form when the principal tensile strain exceeds the tensile capacity of concrete and these diagonal cracks typically propagate from the tension face of the member towards the neutral axis.

There are conventionally considered to be six contributing factors by which a reinforced concrete beam can carry shear, Figure 1. When present, shear reinforcement carries stress over cracks as they open under loading and confines the section. Although aggregate interlock is estimated to carry significant shear force in the uncracked section [1], as cracks open the capacity to transfer stresses via aggregate interlock is minimal [2]. Dowel action by longitudinal reinforcement is contentious, with Kotsovos [2] showing it to be extremely limited in the prismatic section.

The behaviour of prismatic and tapered concrete sections in shear is compared in Figure 1. In sections that taper towards their supports, the interaction of the diagonal cracks with the path of the compression force at the supports is assumed to be critical.

Inclined compression or tension forces can theoretically affect the shear resistance of the section. It is suggested [3-7] that for sections whose depth increases in the direction of increasing moment 
an effective shear force for design be given by Eq. (1), which is valid for members with shear reinforcement:

$$
V_{E d}^{\prime}=V_{E d}-V_{c c d}-V_{t d}
$$

Where $V_{E d}^{\prime}$ is the reduced design shear force; $V_{E d}$ is the shear force on the cross section; $V_{c c d}$ is the vertical component of force in the inclined compression chord and $V_{t d}$ is the vertical component of the inclined tension chord. $M_{E d}$ is the moment on the cross section.

Provided suitable limits on stress in the web compression strut are not exceeded, the sum of $V_{c c d}$ and $V_{t d}$ (Eq.(1)) could theoretically be made equal to the applied shear force, negating requirements for transverse steel. For a beam with yielding tension reinforcement of constant area $\left(A_{s}\right)$ and without normal force this could be achieved by placing the bar at an effective depth that is proportional to the bending moment at each point along the beam (Eq.(2)). Such an approach would make the vertical component of force in the bar $\left(V_{t d}\right)$ theoretically equal to the applied shear force, Eq.(3).

$$
z_{i}=\frac{M_{E d, i}}{A_{s} f_{y k}}
$$

$$
V_{E d, i}=\frac{d M_{E d, i}}{d x}=V_{t d, i}
$$

Where $z_{i}$ is the lever arm between tension and compression forces at position $i ; M_{E d, i}$ is the applied moment at position $i$; $A_{s}$ is the constant area of longitudinal reinforcement and $f_{y k}$ is its characteristic yield strength; $V_{E d, i}$ is the applied shear force at position $i ; d x$ is an increment of length and $V_{t d, i}$ is the vertical component of force in the bar at position $i$.

However, utilising a longitudinal bar to provide vertical force capacity close to the supports in a simply supported beam requires the bar to be fully anchored at its ends and yielded along its entire length. Furthermore, for a structure subject to an envelope of loads the longitudinal reinforcement position will be determined by the maximum moment on each section. It is feasible that the maximum moment and shear forces on a section will not originate from the same load case. In such a situation, a bar placed for moment capacity will then be incorrectly inclined to provide the desired 
vertical force, and thus additional transverse reinforcement will be required.

\subsection{Design methods}

\subsubsection{Truss model}

ACI 318 [8] and BS EN 1992-1-1 [4] allow the shear capacity of a tapered section with transverse reinforcement to include the effects of inclined tension and compression forces, Eq. (1). Both codes are based on the truss analogy, the premise of which $[9,10]$ is that cracked concrete in the web resists shear by a diagonal uniaxial compressive stress in a concrete strut, pushing the flanges apart and causing tension in the stirrups that are then responsible for holding the section together. With a compression strut angle of $45^{\circ}$, the model consistently underestimates shear strength. To correct this ACI 318 [8] adds a 'concrete contribution', while BS EN 1992-1-1 [4] assumes that once cracked the concrete provides no contribution to shear capacity and instead allows a flatter strut angle (down to $22^{\circ}$, subject to stress limits in the diagonal concrete strut) to be chosen, with both approaches replicating experimental observations.

The additional tensile force, $\Delta \mathrm{F}$, arising from the normal stress components of the inclined web compression struts of the truss model $[4,8]$ must be included when calculating the force in the inclined chords to prevent over-estimation of the contribution of an inclined chord to shear capacity.

\subsubsection{Compressive force path method}

The compressive force path (CFP) method premises that the behaviour of a reinforced concrete beam can be simplified into three elements - a concrete frame, a steel tie of flexural reinforcement and a zone of concrete cantilevering teeth which form between successive cracks in the concrete section [11], Figure 2. The uncracked compression zone is proposed to sustain both the compressive flexural force and the entire shear force. Since concrete fails in tension, those regions of the path where tensile stresses may develop will be critical [11].

Experimental data for beams subject to point loads tested by Kotsovos [12] suggests that shear stirrups do not have to be provided throughout the shear span in order to allow full flexural capacity to be reached. Since beams without continuous transverse tension reinforcement cannot conform to the truss analogy, the implication is that "truss behaviour of a section is not a necessary condition 
for a beam to attain flexural capacity once shear capacity is exceeded" [12].

CFP-designed indeterminate frames were compared to ACI 318 [13] by Salek et al [14]. It was found that the CFP-designed frames provided greater ductility through their positioning of transverse reinforcement to carry tensile forces arising from changes in the direction of the compressive force path. Jelic [15] also found that CFP-designed reinforced concrete beams could provide greater ductility with less transverse reinforcement than an equivalent truss-analogy based design.

Whilst the literature suggests that the CFP method provides an accurate representation of the behaviour of reinforced concrete beams, the design method is based on empirical equations [16-18] and non-prismatic elements were not included in their original derivation. There is therefore no guarantee that the method is indeed suitable for non-prismatic beams.

\subsubsection{Strut and tie model}

The assumptions implicit in Eq.(2) and Eq.(3) (which were applied in the design of the 'EC2' beam series described later in this paper) require tension and compression forces to be arranged as shown in Figure 3(a). Such a model relies on full anchorage of the reinforcement and exact alignment of forces at the support. Such an alignment is impossible to prove and unlikely to occur with additional moments generated if it is not achieved (Figure 3 (b)).

To overcome this problem, an alternative strut and tie model was developed, Figure 4, in which the flexural tension reinforcement does not provide full shear capacity and is not required to yield in all locations. The first tension tie is then required to carry the majority of the shear force. In the model, the concrete strut capacity is limited to the concrete compressive strength and the ties are limited by the capacity of the yielding steel at each position. In addition a maximum link spacing of $75 \%$ of the effective depth is applied along the beam length, following recommendations for strut and tie modelling [4]. Areas required for anchorage and development of both longitudinal and transverse reinforcement define the overall section geometry.

The proposed model does not require that all the steel is yielding. Instead, plastic behaviour 
(which is desired for a ductile response) is provided by ensuring that the steel yields in certain positions only. In the proposed methodology, this yielding is to occur at the position of maximum moment and beam depth, and away from the support location. It is proposed that this mechanism will provide ductility to the beam response. At the failure load, it is likely that reinforcement at the support will still be in its elastic range.

\subsection{Test data} concrete beams in shear. Debaiky and El-Neima [5] compared prismatic and tapered beams in a series of 33 tests. Crack number and location were found to depend on the inclination of the beam haunch. Compared to a prismatic section, the total number of cracks was found to increase for negatively haunched beams and to decrease for positively haunched beams (Figure 5). For positive haunches, the position of the major shear crack moved closer to the support, as would be expected based on an assumption that cracking occurs at the weakest section.

T-beam specimens tested later by El-Neima [19] showed similar results, with both positive and negative haunch sections showing lower shear capacities than prismatic sections. Further tests [5, 19] showed reductions in shear capacity for haunched beams, suggesting variable section beams could negatively affect the shear capacity of the section.

Haunched beams carrying hogging in continuous beams could benefit from shear capacity provided by the inclined compression zone. Macleod and Houmsi [6] and later Rombach and Nghiep [7] found that the additive method described by Eq. (1) could result in unconservative capacity predictions for sections with inclined compression zones (without shear reinforcement). It was recommended [7] that only $50 \%$ of the value of $V_{c c d}$ should be included (if it is a favourable effect), Eq.(4):

$$
V_{E d}^{\prime}=V_{E d}-0.5 V_{c c d}
$$

The limited available experimental data suggests that additive methods for the shear capacity of tapered beams can lead to unconservative results. This highlights the fact that the underlying 
behaviour is not yet fully understood. This behaviour, of crucial importance for non-prismatic beams, is assessed in this paper through a series of beam tests.

\section{Design}

To determine the most appropriate method for the design of tapered beams in shear, 19 tests on 11 beam specimens were undertaken to consider:

1. Design using the variable angle truss model ('EC2');

2. Design using the compressive force path method ('CFP'); and

3. Design using a proposed strut and tie model ('STM').

\subsection{Methodology}

Tapered beams with shear spans of 150,300, 500 and 1000mm were designed using the EC2 and CFP methods; only a 500mm shear span was considered in the STM approach due to time limitations. All beams had a total span during testing of $2000 \mathrm{~mm}$. Beams with shear spans of $\leq 500 \mathrm{~mm}$ were cast with two tapered ends and tested twice, as shown in Figure 6 . The beams are named according to shear span and design methodology, with EC2 and CFP beams predicted failure modes being denoted by $V$ (predicted shear failure) or $M$ (predicted flexural failure).

All beams had a constant breadth of $110 \mathrm{~mm}$ and were reinforced on their tension face with two $10 \mathrm{~mm}$ diameter high yield U-bars to provide full anchorage at the support zone. Where links are used, these are $3 \mathrm{~mm}$ diameter high yield plain bars as closed links. The links are anchored around two $3 \mathrm{~mm}$ plain bars used as top steel (which provides a negligible contribution to flexural capacity). The concrete design strength was $40 \mathrm{MPa}$. Cover to the longitudinal tensile reinforcement was $20 \mathrm{~mm}$. A summary of the beam nomenclature and design loads is provided in Table 1 . The relationship between the test load, $\mathrm{P}$, and the design shear force, $\mathrm{V}_{\mathrm{Ed}}$, has been arranged such that for Beams $2-4$ a comparable shear force is imposed on the tapered end. 
Table 1: Summary of test loads and maximum shear force

\begin{tabular}{|l|l|l|l|l|}
\hline Test & Designs & Test load, P & Shear span, $\mathbf{a}_{\mathbf{v}}$ & $\begin{array}{l}\text { Design shear force at the } \\
\text { tapered end, } \mathbf{V}_{\mathbf{E d}}\end{array}$ \\
\hline $1 *$ & EC2 / CFP & 32 & 1000 & $16 \mathrm{kN}$ \\
\hline 2 & EC2 / CFP / STM & 36 & 500 & $27 \mathrm{kN}$ \\
\hline 3 & EC2 / CFP & 31.8 & 300 & $27 \mathrm{kN}$ \\
\hline 4 & EC2 / CFP & 29.2 & 150 & $27 \mathrm{kN}$ \\
\hline$*$ Beam 1 was symmetrical, with point load applied at midspan of the 2000mm long beam \\
\hline
\end{tabular}

173

174

175

176

177

178

179

180

181

182

184

\subsection{Beam design}

\subsubsection{EC2 model}

The EC2 beams series were designed according to the method described by Eq.(2) and Eq.(3) and uses the vertical component of force in the yielding longitudinal steel as an effective shear link. Iteration is carried out to find the geometry that satisfies equilibrium and provides the full flexural and shear requirements at each point along the beam. Anchorage of the bar is provided by the use of U-bars. A check was also made to ensure that the steel was able to yield under the applied loads. Such an approach, which implies that flexural and shear failures are equally likely, was denoted ' $V$ ' (predicted shear failure).

Taking the same geometry as the ' $V$ ' series beams, EC2 beams with predicted flexural failures (denoted ' $M$ ') disregarded the potential shear contribution of inclined longitudinal steel and used only yielding transverse reinforcement designed according to BS EN 1992-1-1 [4] (Eq.(6.8)) to provide shear capacity. The strut inclination was typically $21.8^{\circ}$, and $V_{R d, m a x}$ was not a governing criteria. A concrete compressive strength of 40MPa, and steel yield strength of 500MPa, where used in the design and all partial safety factors were set to 1.0. The four beam elements, designed to the loads and shear spans given in Table 1 are shown in Figure 7.

\subsubsection{Compressive force path (CFP)}

The CFP method was applied by considering the two potential failure modes for the section: ductile flexure or brittle flexure-shear. An empirical equation for the moment corresponding to shear failure $\left(M_{c x}\right)$ is used for design and given by Eq.(5) $[16,17,20]$.

$$
M_{c x}=0.875 a_{v x} d\left(0.342 b_{1}+0.3 \frac{M_{f}}{d^{2}} \sqrt{\frac{z}{a_{v x}}}\right) \sqrt[4]{\frac{16.66}{\rho_{w} f_{y}}}
$$




$$
V_{c x}=\frac{M_{c x}}{a_{v x}}
$$

Where the subscript $x$ denotes a given cross-section at a distance $x \mathrm{~mm}$ from the support; $M_{c x}$ is the moment corresponding to shear failure $(\mathrm{Nmm}) ; M_{f}$ is the flexural capacity $(\mathrm{Nmm}) ; a_{v x}$ is the ratio $M_{a x} / V_{a x}(\mathrm{~mm}) ; M_{a x}$ and $V_{a x}$ are the applied bending moment $(\mathrm{Nmm})$ and shear force $(\mathrm{N})$ on the section; $z$ is the lever arm $(\mathrm{mm}) ; d$ is the effective depth $(\mathrm{mm}) ; \rho_{w}$ is the ratio of the area of tension steel to the web area of concrete to effective depth; $f_{y k}$ is the characteristic strength of the tension steel $\left(\mathrm{N} / \mathrm{mm}^{2}\right) ; b_{w}$ is the web width $(\mathrm{mm})$; and $V_{c x}$ is the shear force at failure.

The design method was originally applied to prismatic beams. For variable section members, the beam is divided into sections, and at each section the required effective depth for flexural capacity according to the plane sections theory is determined. Each section is then assessed against Eq.(5) to determine a value of $M_{c x}$ for the section, with a corresponding shear capacity given by Eq.(6). The effective depth at each point along the length of the beam is iterated until either $V_{f}$ or $V_{c x}$ exceeds the design shear at each point.

A graph of the applied moment-shear envelope $\left(V_{a}, M_{a}\right)$, the moment and shear forces corresponding to flexural failure $\left(M_{f}, V_{f}\right)$ and the moment and shear forces corresponding to shear failure $\left(M_{c x}, V_{c x}\right)$ are then plotted (shown in Figure 8 for a beam subject to multiple point loads).

From this two types of failure mode can be designed for. The first, shear failure (denoted ' $V$ '), requires only that the shear capacity at each point on the beam be equal to the applied load envelope. In the support zones $V_{c x}$ therefore governs the failure mode.

The second mode is to ensure flexural failure in the entire beam (denoted ' $M$ '). This is achieved by adding shear capacity to all positions on the beam at which $V_{c x} \leq V_{f}$ until flexural failure is predicted to occur before shear failure. In the end zones, considerable transverse reinforcement was required to achieve this, Eq.(7).

$$
A_{s}=\frac{V_{f}-V_{c x}}{f_{y k}}
$$

Where $V_{f}$ is the shear force corresponding to flexural failure; $V_{c x}$ is given by Eq.(6) and $f_{y k}$ is the 
characteristic steel yield strength.

Following the proposed method four beams were designed with one end predicted to fail in shear

(' $V$ ') and one end in flexure (' $M$ '). The resulting beam layouts are shown in Figure 9. The curved

end of the beam arises as a result of the design method and was constructed using bespoke formwork.

\subsubsection{Strut and tie model (STM)}

The strut and tie model is shown in Figure 4 and is differentiated from the EC2 model as it does not require the steel to be yielding everywhere within the tapered zone (the steel should be yielding at the position of maximum moment to provide plastic behaviour). Design is initiated by calculating the required depth at the position of maximum moment that will ensure the predefined area of internal flexural steel reinforcement steel has yielded in this location. The actual, rather than characteristic, yield strength of the steel should be used. This provides the overall geometry of the beam, with the force in each section limited by concrete crushing and steel yielding (each element is not required to be at maximum stress). Tension paths are required to form a straight line between nodes. At each node, equilibrium considerations provide the forces in each tie and thus the area of transverse reinforcement required.

The model geometry is iterated to provide a reinforcement layout with the required shear and

flexural capacities, resulting in the beam shown in Figure 10. At the support, the forces must still

line up quite precisely, so one end of the beam was cast around a steel angle anchored into the concrete by a $10 \mathrm{~mm}$ diameter reinforcing bar. This is the only difference between the two ends of the tapered STM beams (denoted ' 1 ' without the end angle and ' 2 ' with the end angle).

\section{Testing}

A steel mould was used to create each beam profile (Figure 7, Figure 9 and Figure 10). Longitudinal and transverse reinforcement was cut and bent to shape in the laboratory using prepared templates for each beam. The beams were cast in sets of four, demoulded after 3 days and cured in laboratory conditions prior to testing. 
The test set up for each beam is shown in Figure 11. This setup has been carefully chosen to

allow each specimen to be tested twice. The first test has only a minor effect on the prismatic zone, and no effect on the tapered zone, of the second test. Steel strains in the flexural reinforcement were monitored at three positions in the tapered section with strain gauges. High definition video and still images were recorded for post-processing using digital image correlation to determine strains on the concrete surface.

\subsection{Materials}

All specimens were cast from the same concrete mix design (Table 2). Average cube strengths at 28 days are given in Table 3 . High yield deformed bar was used as longitudinal reinforcement (characteristic yield strength, $f_{y k}=500 \mathrm{MPa}$, average yield strength according to tests $f_{y}=562 \mathrm{MPa}$ ), undeformed high yield bar was used as transverse reinforcement. The aggregate (see Table 2) was provided in accordance with the requirements of BS EN 12620 [21].

Table 2: Concrete mix design per $\mathrm{m}^{3}$

\begin{tabular}{|l|l|l|l|}
\hline Cement (CEM IIbv) & 4-8mm aggregate & 0-5mm aggregate & Water \\
\hline $450 \mathrm{~kg}$ & $1055 \mathrm{~kg}$ & $705 \mathrm{~kg}$ & $190 \mathrm{~kg}$ \\
\hline
\end{tabular}

Table 3: Recorded 28 day concrete cube compressive strength

\begin{tabular}{|l|l|l|}
\hline Age & Average compressive strength (MPa) & Standard deviation (MPa) \\
\hline 28 days & 47.9 & 3.8 \\
\hline
\end{tabular}

\subsection{Test results}

A summary of all the tests is provided in Table 4. Crack patterns at failure for all beams are provided in Figure 12. Load-displacement plots (normalised for design maximum load) are shown in Figure 13, Figure 14 and Figure 15. Beam 4_CFP_V results are omitted due to test problems.

The transverse reinforcement ratio $\left(\rho_{\mathrm{w}}=\mathrm{A}_{\mathrm{sw}} / \mathrm{s} / \mathrm{b}_{\mathrm{w}}\right)$ within the shear span for each beam is given.

Table 4: Test failure modes and ultimate capacity

\begin{tabular}{|l|l|l|l|l|l|l|}
\hline & $\boldsymbol{\rho}_{\mathrm{w}}(\boldsymbol{\%})$ & $\begin{array}{l}\text { PIV } \\
\text { collected } \\
\text { (Yes/No) }\end{array}$ & $\begin{array}{l}\text { Design } \\
\text { maximum load, } \\
\mathbf{P}(\mathbf{k N})[\mathbf{A}]\end{array}$ & $\begin{array}{l}\text { Maximum load } \\
\text { achieved in test } \\
(\mathbf{k N})[\mathbf{B}]\end{array}$ & Failure mode & $\begin{array}{l}{[\mathrm{B}] /} \\
{[\mathbf{A}]}\end{array}$ \\
\hline 1_EC2_V & 0.00 & $\mathrm{~N}$ & 32.0 & 19.0 & Shear & 0.59 \\
\hline 2_EC2_V & 0.00 & $\mathrm{Y}$ & 36.0 & 28.2 & Shear & 0.78 \\
\hline 2_EC2_M & 0.28 & $\mathrm{Y}$ & 36.0 & 32.1 & Shear & 0.89 \\
\hline 3_EC2_V & 0.00 & $\mathrm{~N}$ & 31.8 & 17.1 & Shear & 0.54 \\
\hline 3_EC2_M & 0.47 & $\mathrm{Y}$ & 31.8 & 18.8 & Shear & 0.59 \\
\hline 4_EC2_V & 0.00 & $\mathrm{~N}$ & 29.2 & 26.1 & Shear & 0.89 \\
\hline 4_EC2_M & 0.69 & $\mathrm{~N}$ & 29.2 & 9.6 & Anchorage & 0.33 \\
\hline
\end{tabular}




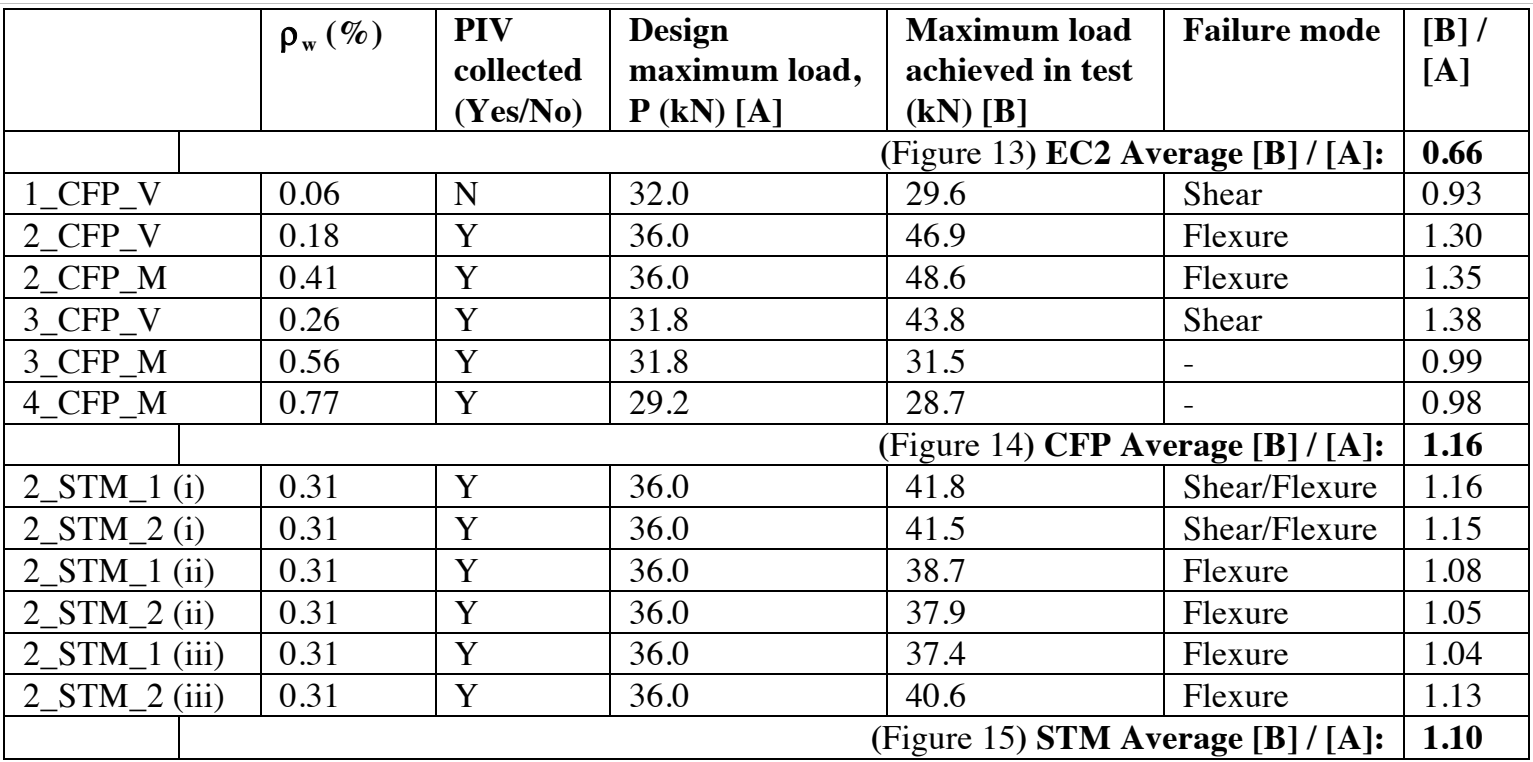

\subsection{Discussion}

The results of nineteen beam tests undertaken on eleven specimens are presented in Figure 13.

On average, beams designed using the 'CFP' method exceeded their design load by $16 \%$, those designed using the 'STM' method by $10 \%$ and the 'EC2' beams were found to be unconservative, falling short of the design load by $34 \%$ on average.

The results suggest that the EC2 design method can lead to unconservative designs for tapered beams in shear. Both the CFP and STM models provide consistent, conservative, results. Within the STM test series, tests with and without external steel plates anchored into the section with a horizontal bar showed no difference in global behaviour.

The tests suggest that simplified optimisation methods may not necessarily be appropriate for elements of complex geometry and some existing design guidance may be inappropriate for the shear design of tapered beams.

\section{Digital Image Correlation}

Digital image correlation (DIC) was used to monitor strain distributions in the concrete. DIC 284 beam, which is then processed to determine displacement and strain distributions. The freeware software MatchID [22] was used to carry out the analysis. 


\subsection{Results}

DIC data was collected for each test as described in Table 4. Figure 13 shows that the design methods give contrasting behaviour under loading. The CFP beams displayed ductility in combinations of flexure and flexure-shear failure. By contrast, all the EC2 beams failed in a less desirable brittle manner. The STM model provides ductility through a design method that does not rely on assumptions of steel yielding or on empirical equations for shear behaviour.

In the EC2 test series, elements with transverse reinforcement (denoted ' $M$ ') were found to behave almost identically to those without transverse reinforcement (denoted ' $V$ '), Table 4 . It was proposed in the design model for ' $\mathrm{V}$ ' type beams that the inclined steel reinforcement would both carry the entire shear force and act as flexural reinforcement. This was not achieved, as the beams failed to reach their design loads, but more importantly there was no significant difference in failure load between the ' $\mathrm{V}$ ' and ' $\mathrm{M}$ ' type beams. This suggests that the transverse reinforcement, which is generally placed in concrete sections to increase their shear capacity, did not achieve this.

By contrast, the effective placement of transverse reinforcement forms a central design criterion for the CFP method, with vertical steel provided only where it is needed in positions where tension forces are developed [11].

\subsection{Analysis}

Differences between the design methods are highlighted in Figure 16, where principal strains $\varepsilon_{1}$ and $\varepsilon_{2}$ for Beam 2_EC2, Beam 2_CFP_M and Beam 2_STM_2(i) are presented at their respective peak loads. Also shown in Figure 16 is an overlay of reinforcement locations and crack patterns at failure. The plots illustrate how the distribution of strains differs by design method. In the EC2 beam, which failed at an applied load $14 \mathrm{kN}$ less than that for the CFP beam, a strain concentration in the support zone can been seen, while much lower strains in the 'body' of the tapered beam are evident.

By contrast, strains in the CFP beam are at their greatest concentration beneath the load point, at the position of maximum moment. Moving from this position to the support location, three bands of 
inclined zones of higher strain can then be seen in the $\varepsilon_{2}$ plot, with the magnitude of the maximum strain at the support being lower than that in the EC2 Beam. These zones can be imagined to demarcate the concrete 'teeth' described by the CFP model. This is further reflected by the much deeper cracking that was able to occur before failure in the CFP beam.

In the EC2 beam, cracks at the support dominate the failure mode. A line drawn over the top of the maximum crack depth for the 2_EC2_M and 2_CFP_M beams shows how the EC2 design is governed by the end zone, suggesting a shear critical design method. In the CFP designed beam, the neutral axis (denoted by the tip of the cracks) is almost horizontal in the tapered section of the beam, suggesting a greater utilisation at its peak load.

Figure 17 compares principal strains for the three design methods at the failure load of the EC2 beam $(32 \mathrm{kN})$, further demonstrating the changes described above. Beams 3_EC2 and 3_CFP were found to display the same general behaviour as those of the 2_EC2 and 2_CFP. In Beam 3_EC2_M, a peak of principal strain $\varepsilon_{2}$ was seen at the supports just prior to failure (which occurred at just over half of the design load). This contrasts to the behaviour of Beam 3_CFP, Figure 18, and provides additional weight to the analysis and comparisons between the EC2 and CFP models described above.

It is thus shown that by controlling the compression path the CFP method is better able to facilitate a conservative design prediction whose failure mode is also predicted. DIC analysis presented in this section has shown how the behaviour of the EC2 and CFP beams differ, and whilst data was not collected for all the EC2 beams, their failure modes recorded during testing are consistent with the behaviour seen in Beam 2_EC2 and described above.

The crack and strain distributions seen in the STM beam series demonstrate the advantages of the design method. By moving strain concentrations away from the support, where their influence in the EC2 beam has been seen to cause premature shear failures, the STM beams fail in a ductile manner as shown in Figure 13.

The STM beams have a deeper support section than those designed using the EC2 model. This 
results from anchorage and development length requirements for transverse reinforcement, coupled with the model stipulation for straight lines between tension nodes. The minimum STM depth was almost identical to that for the CFP method. In the STM design model, all the forces in the beam during loading are predicted. During testing, strains in the longitudinal tension steel were recorded. It is thus possible to compare the predicted and actual load distribution in the beam, as shown in Figure 19 at the design load $(36 \mathrm{kN})$.

The presence of a high vertical strains a small distance from the support in the STM beam was correlated to the design layout using the DIC data. The contribution of the first vertical link in the STM design is critical as the force in this link is approximately equal to the full reaction. It is further shown in Figure 19 that the forces predicted in the model correlate well to the recorded steel strains.

The STM model provides advantages to the beam design by moving areas of high tension away from the support zone. Whilst the STM and CFP beams both failed in a ductile manner, it may be surmised from these plots that the STM beam was closer to a brittle failure than the CFP beam. This suggests that CFP the method is an appropriate and conservative design approach.

\section{Discussion}

A comparison between the overall profiles of the end zone of the three beam types is provided by Figure 7, Figure 9 and Figure 10. Whilst the shallow support zone of the EC2 beam might be expected to yield the lowest capacities, it is the manner in which the STM and CFP models are able to adjust and control the behaviour of the beams that is most relevant about these results. This is demonstrated by comparing reinforcement ratios for the test specimens (Table 4). For example, Beam 2_CFP_V has less transverse reinforcement than Beam 2_EC2_M (0.18\% versus 0.28\%), but achieves a higher failure load $(46.9 \mathrm{kN}$ versus $32.1 \mathrm{kN})$. The failure loads of Beam 2_CFP_V and Beam 2_STM_1 are similar $(46.9 \mathrm{kN}$ versus $41.8 \mathrm{kN})$, but the beams have quite different transverse reinforcement ratios $(0.18 \%$ versus $0.31 \%)$. It is only by pushing the EC2 model to its feasible limit that the deficiencies in such an approach are revealed. 


\subsection{Crack progressions}

The progression of cracking is summarised for all Beam 2 variants in Figure 20. The EC2 beams were found to crack initially at the end zone (regions of high strain seen in the DIC results) before limited crack progression towards the point of load application. In the STM model, cracking begins in the centre of the tapered zone before spreading towards the support and the point of load application. In the CFP model, cracking begins beneath the load point and spreads towards the support before failure.

These patterns of crack progression are seen in all the beams tested and highlight the shear critical nature of the EC2 design. By cracking first in the end zone, it is clear that shear is the dominant condition at the ultimate load, and thus a brittle failure is created.

The EC2 model is, in itself, a strut and tie model that assumes the steel yields so that plastic behaviour is possible and stresses may be redistributed. This approach forms the basis of the BS EN 1992-1-1 [4]. The STM model, in which the steel is not assumed to be yielding in all positions, is therefore based on lower bound plasticity theory but is applied to a situation where the behaviour is not plastic. The success of the STM model is found in providing a conservative design method for tapered beams that do not fail in shear. Ductile behaviour is ensured by controlling the yielding position such that it occurs away from the support (in the beams tested in this paper it occurs primarily beneath the loading point). This provides the element with the ductile behaviour that is desired in the design process, something that may not be guaranteed by the EC2 method.

In this way, the STM and EC2 models are opposite in their approach. Whereas the STM model becomes a self-fulfilling prophecy in which the section can be designed to be ductile and so it is ductile, the EC2 model can become a vicious circle in which the ductile failure that is desired cannot be achieved because the steel is not able to yield prior to failure of the critical section. This fundamental result demonstrates the power of the STM method over the EC2 approach described in this paper. 


\section{Conclusions}

This paper has shown that the STM and CFP methods provide reliable design processes that result in an advantageous internal strain distribution, while the EC2 method does not marry with the experimental data. The importance of the compression path in shear behaviour is demonstrated by the CFP and STM design methods. In both, the change in direction of the compression path gives rise to the critical link position.

The test results (Figure 13) show that the EC2 model is shear critical and unconservative, while the STM is less shear dominant than the EC2 model, and the CFP model provides perhaps the ideal behaviour (limited cracking and lower strains in the end zone, leading to predictable and ductile failures).

Results from both the CFP and STM beam design methods, supported by DIC data, suggest that they are better able to model the behaviour of tapered beams in shear. In light of the results presented for the EC2 beam series, it is recommended that tapered beams do not rely entirely on the contribution of their flexural steel to provide shear capacity. This means that the value of the vertical component of the steel force $\left(V_{t d}\right)$ should not comprise the full value of the shear resistance of the section until further guidance can be determined. The DIC analysis shows that the tension zones seen in the support zone of EC2 beams is moved in both the STM and CFP beams to a distribution across the taper that satisfies the design model.

Only simply-supported beams have been considered in this paper, and many more challenges and opportunities will arise through the use of non-prismatic beams in frame elements, or in cast in-situ construction where the support conditions allow moments to be carried. This introduces additional 410 challenges for the optimisation of concrete structures.

\section{Notation}

\begin{tabular}{|l|l|}
\hline $\mathrm{A}_{\mathrm{sw}}$ & Area of transverse reinforcement $\left(\mathrm{mm}^{2}\right)$ \\
\hline$a_{v x}$ & $M_{a x} / V_{a x}(\mathrm{~mm})$ in the CFP method \\
\hline $\mathrm{b}_{\mathrm{w}}$ & Web width $(\mathrm{mm})$ \\
\hline$d x$ & An increment of length \\
\hline$f_{v k}$ & Characteristic yield strength of steel reinforcement \\
\hline$M_{a x}$ & Applied bending moment (Nmm) on a section in the CFP method \\
\hline$M_{c x}$ & Is the moment corresponding to shear failure (Nmm) in the CFP method \\
\hline
\end{tabular}




\begin{tabular}{|l|l|}
\hline$M_{E d, i}$ & The applied moment at position $i$ \\
\hline$M_{f}$ & The flexural capacity (Nmm) in the CFP method \\
\hline $\mathrm{s}$ & Transverse reinforcement spacing (mm) \\
\hline$V_{E d}^{\prime}$ & The reduced design shear force, Eq.(1) \\
\hline$V_{a x}$ & Applied shear force (N) on a section in the CFP method \\
\hline$V_{c x}$ & Shear force at failure in the CFP method \\
\hline$V_{E d, i}$ & The applied shear force at position $i$ \\
\hline$V_{f}$ & Shear force corresponding to flexural failure in the CFP method \\
\hline $\mathrm{V}_{\mathrm{td}}$ & Vertical component of force in the bar \\
\hline$V_{t d, i}$ & The vertical component of force in the bar at position $i$ \\
\hline $\mathrm{x}$ & (subscript) denotes a given cross-section at a distance $x$ mm from the support in the CFP method \\
\hline$z_{i}$ & The lever arm between tension and compression forces at position $i$ \\
\hline$\rho_{w}$ & Ratio of the area of tension steel to the web area of concrete to the effective depth in the CFP method \\
\hline$\rho_{\mathrm{w}}$ & $\mathrm{A}_{\mathrm{sw}} / \mathrm{s} / \mathrm{b}_{\mathrm{w}}$ (reported in \%) \\
\hline
\end{tabular}

\section{References}

414 [1] Taylor HPJ. Investigation of the forces carried across cracks in reinforced concrete beams in shear by interlock of aggregate. 415 London: Cement and Concrete Association; 1970.

416 [2] Kotsovos MD. Concepts Underlying Reinforced Concrete Design: Time for Reappraisal. ACI Structural Journal. 2007;104:67541784.

418 [3] Park R, Paulay T. Reinforced concrete structures. USA: John Wiley and Sons; 1975.

419 [4] BSI. BS EN 1992-1-1. Eurocode 2: Design of concrete structures - Part 1-1: General rules and rules for buildings. London, UK: 420 BSI; 2004.

421 [5] Debaiky SY, Elneima EI. Behavior and Strength of Reinforced Concrete Haunched Beams in Shear. ACI Structural Journal. 422 1982;79:184-94.

[6] MacLeod IA, Houmsi A. Shear strength of haunched beams without shear reinforcement. ACI Structural Journal. 1994;91:79-89.

[7] Rombach G, Nghiep VH. Versuche zue Querkrafttragfaeghigkeit von gevouteten Stahlbetonbalken ohne Querkraftbewehrung (Shear strength of Haunched Concrete Beams without Transverse Reinforcement). Beton und Stahlbetonbau. 2011;106:11-20.

[8] ACI. ACI 318. Building Code Requirements for Structural Concrete and Commentary: ACI; 2005.

[9] Ritter W. Die bauweise hennebique (Construction techniques of Hennebique). Zurich: Schweizerische Bazeitung; 1899.

[10] Mörsch E. Der Eisenbeton, seine Theorie und Anwendung (Reinforced Concrete, theory and practical application. . Stuttgart: Wittwer; 1908.

[11] Kotsovos MD, Pavlovic MN. Ultimate limit state design of concrete structures, a new approach. London: Thomas Telford; 1999.

[12] Kotsovos MD. Compressive Force Path Concept: Basis for Reinforced Concrete Ultimate Limit State Design. ACI Structural Journal. 1988;85:68-75.

[13] ACI. ACI 318. Building Code Requirements for Structural Concrete and Commentary: ACI; 1989.

[14] Salek MS, Kotsovos MD, Pavlovic M. Application of the compressive-force path concept in the design of reinforced concrete indeterminate structures: A pilot study. Structural Engineering and Mechanics. 1995;3:475-95.

[15] Jelic I. Behaviour of reinforced concrete beams: A comparison between the CFP method and current practice. London: Imperial College London; 2002.

[16] Whitney CS. Ultimate shear strength of reinforced concrete flat slabs, footings, beams and frame members without shear reinforcement. Journal of the American Concrete Institute. 1957;29:265-98.

[17] Bobrowski J, Bardhan-Roy BK. A method of calculating the ultimate strength of reinforced and prestressed concrete beams in combined flexure and shear. The Structural Engineer. 1969;5:197-209.

[18] IStructE. Fire resistance of concrete structures: report of a Joint Committee. London: IStructE, The Concrete Society; 1975.

[19] El-Niema EI. Investigation of haunched concrete T-Beams under shear. ASCE. 1988;114:917-30.

[20] Kotsovos MD, Bobrowski J, Eibl J. Behaviour of reinforced concrete T-Beams in shear. The Structural Engineer. 1987;65B:110 .

[21] BSI. BS EN 12620. Aggregates for concrete. London: BSI; 2008.

[22] Debruyne D, Lava P. Manual for MatchID 2D. Ghent: Catholic University College Ghent; 2011. 


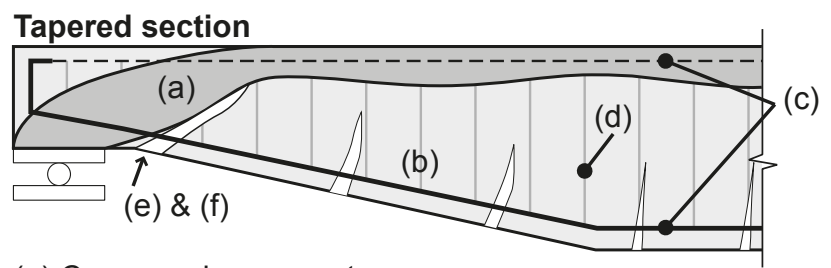
(a) Compression concrete
(b) Tension concrete
(d) Shear reinforcement
(c) Flexural reinforcement
(e) Aggregate interlock
(f) Dowel action

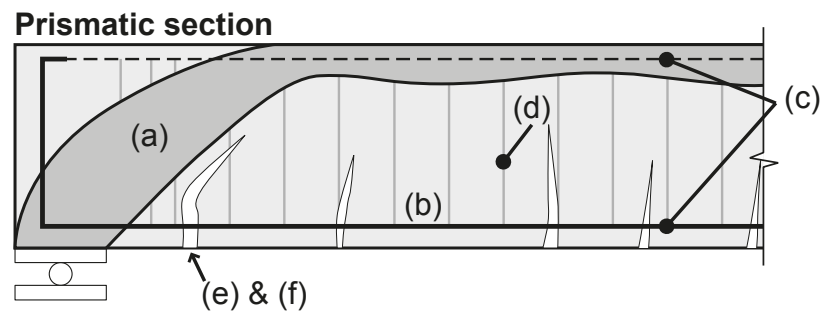

Figure 1: Contributing factors to shear resistance in tapered and prismatic sections.

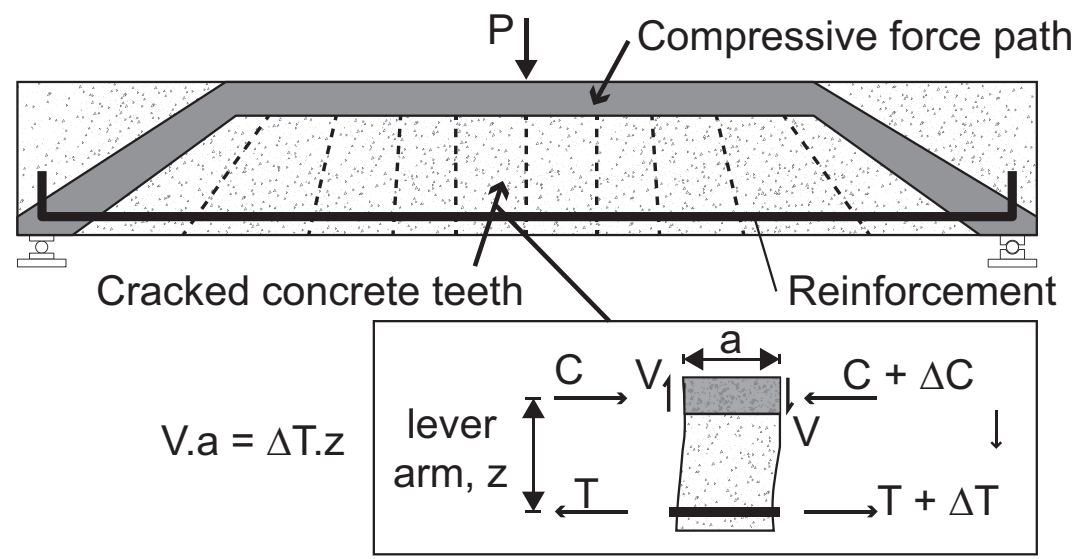

Figure 2: The CFP method [11]

(a)

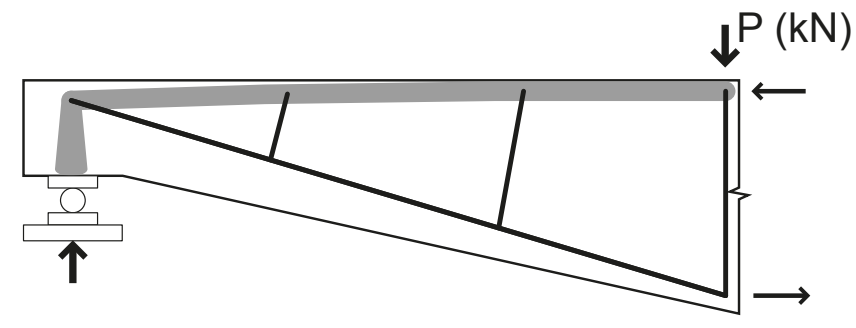

'EC2'

(b)

Position of 'zero' moment capacity is offset from support.

Support cannot carry horizontal force

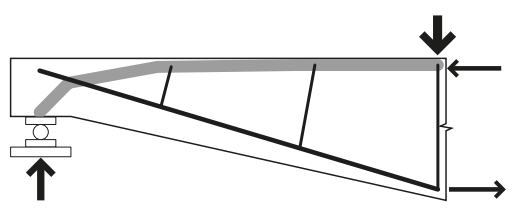

Figure 3: Equivalent strut and tie model assumed for EC2 model (a); potential for moment generation at the supports

(b). 


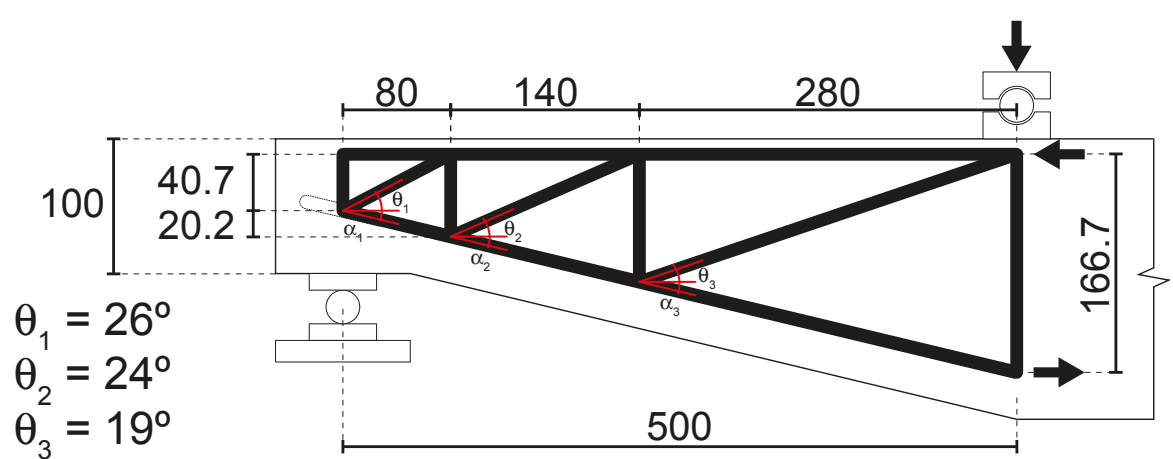

Figure 4: Generic strut and tie model for a tapered section.

'positive haunch'

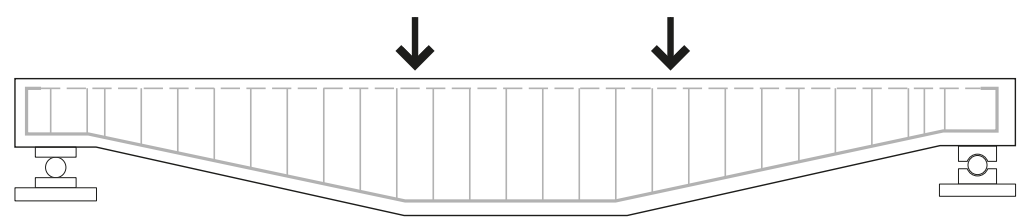

\section{'negative haunch'}

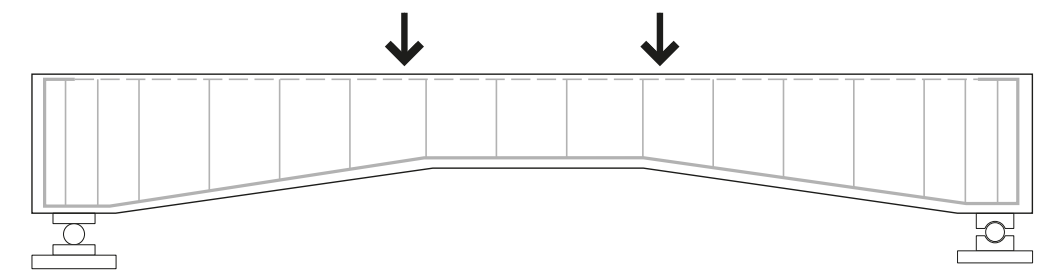

Figure 5: Positive and negative haunch definition

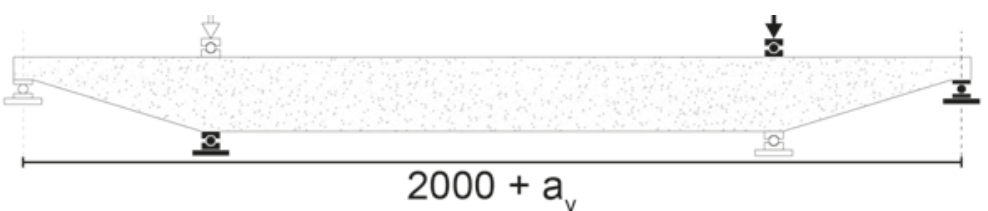

Setup 'M':

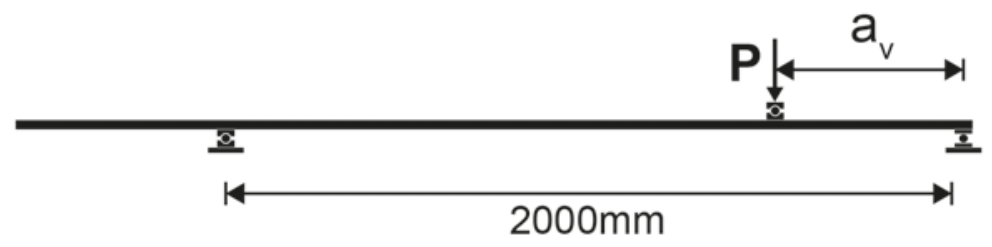

\section{Setup 'V':}

Figure 6: Test loading arrangements

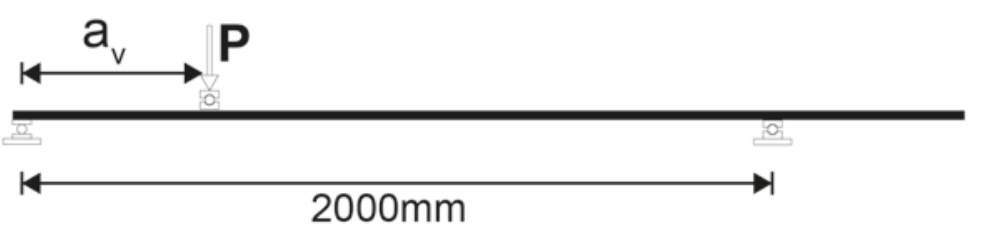




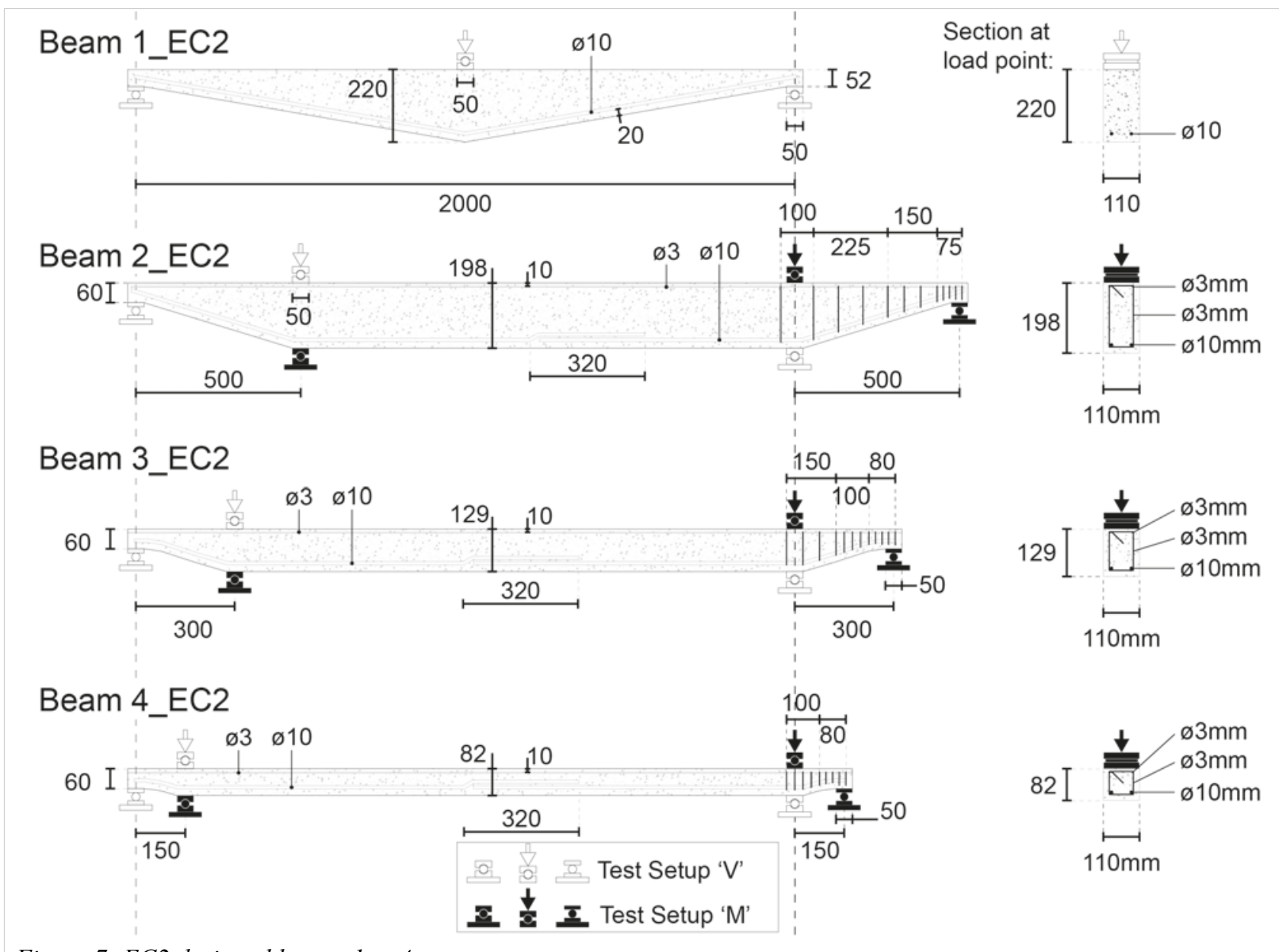

Figure 7: EC2 designed beams 1 to 4.

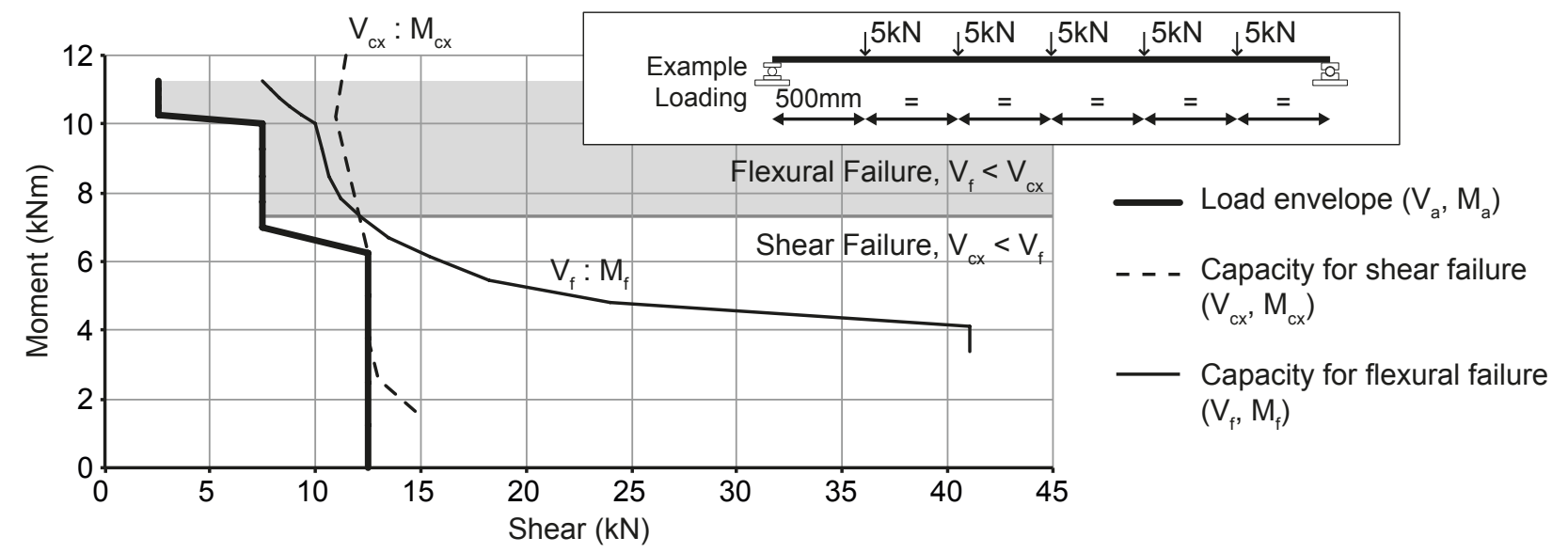

Figure 8: Failure modes and interaction diagram for example beam subject to symmetric loading. 


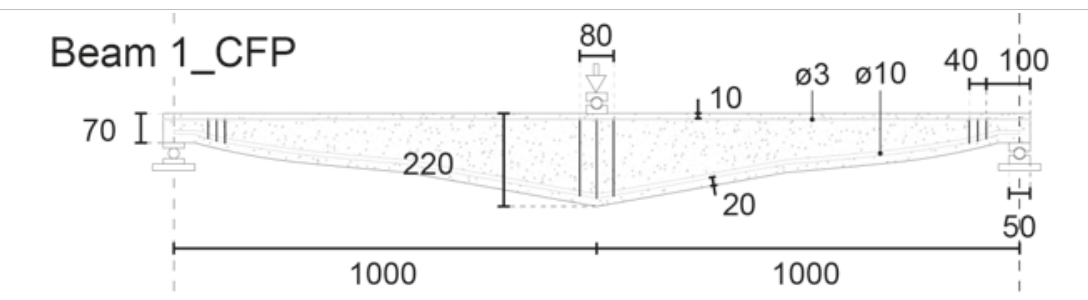

Section at load point:

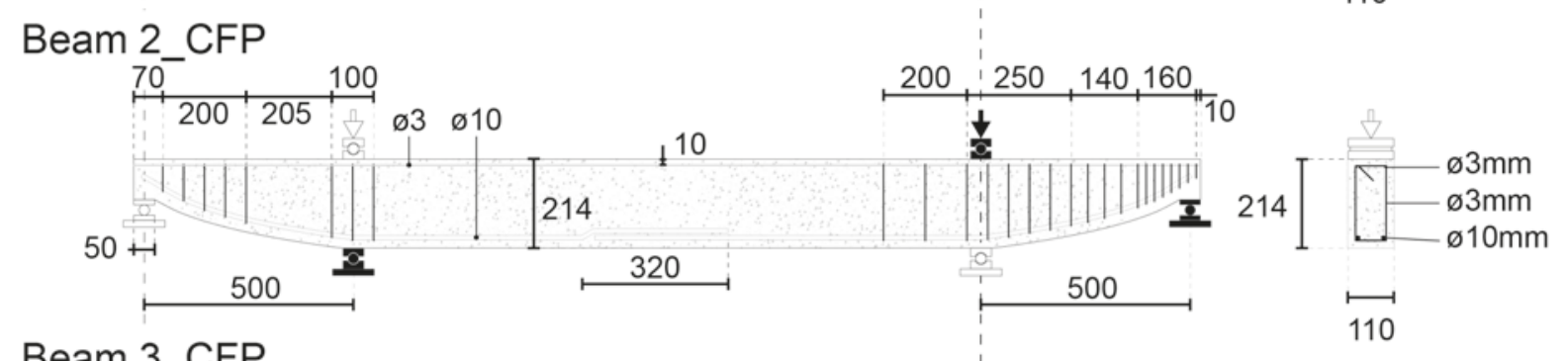

Beam 3_CFP

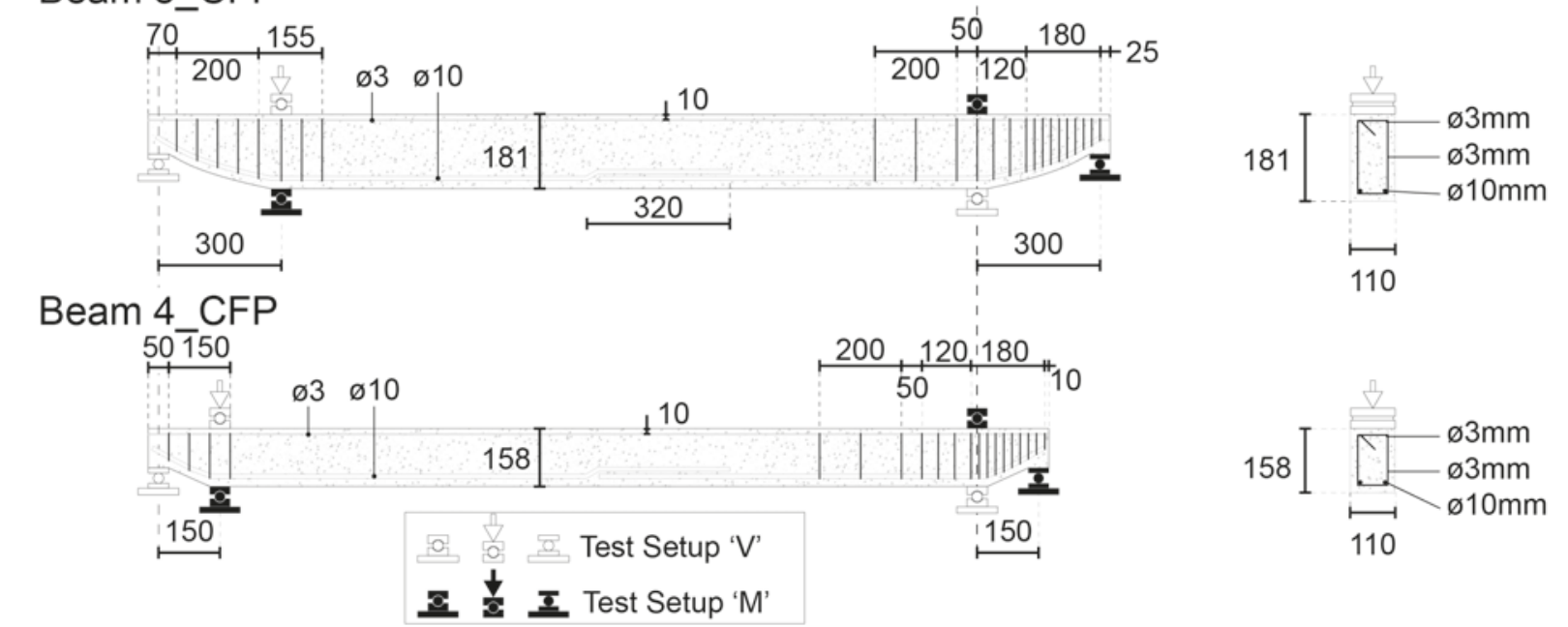

Beam 4 CFP
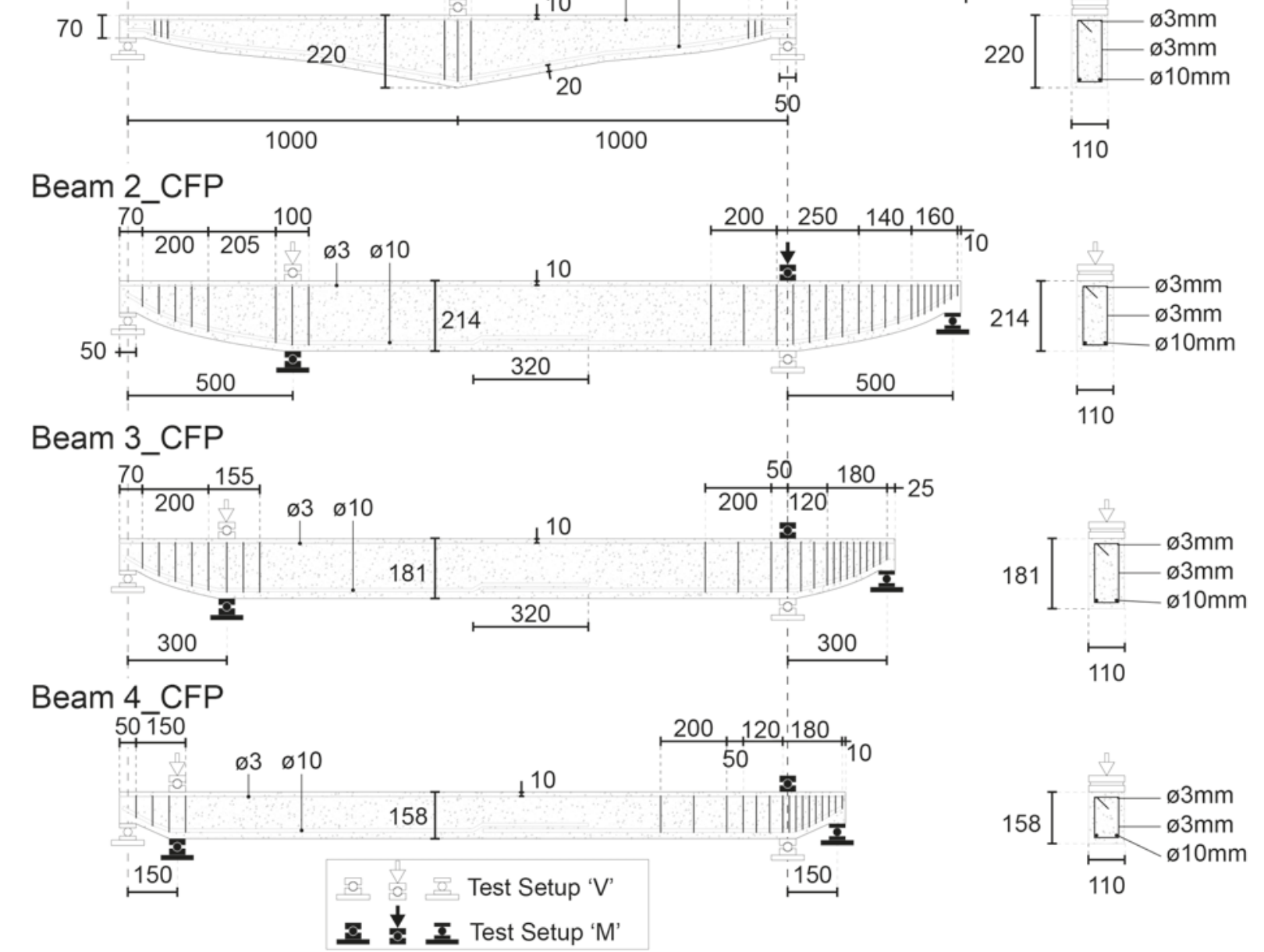

110

Figure 9: CFP designed beams 1 to 4.

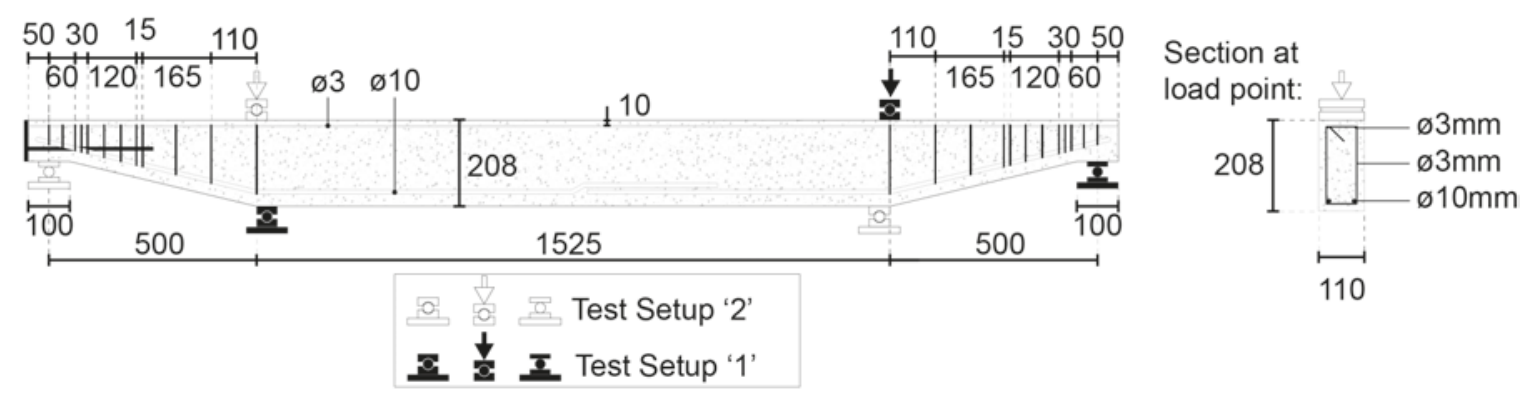

Figure 10: STM design beam 2 
475

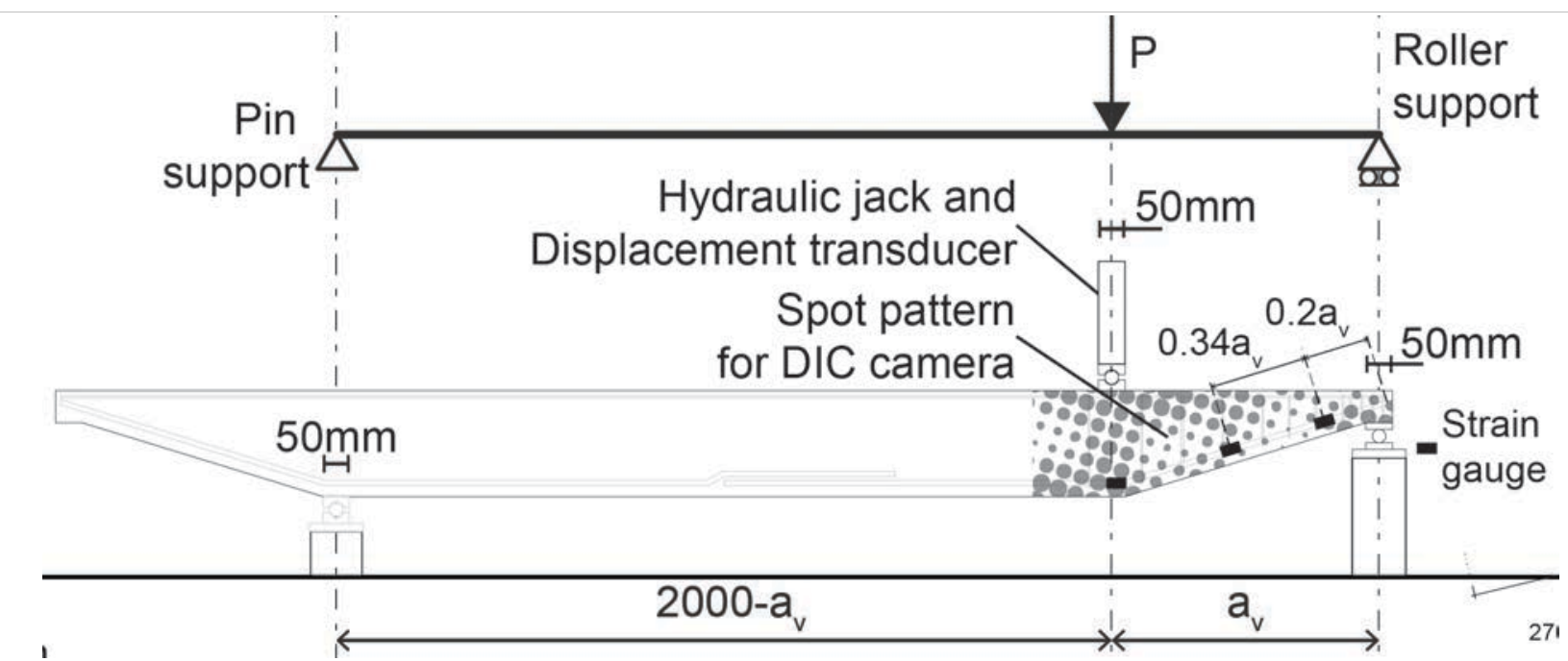

Figure 11: Test layout and monitoring.

Beam 2_CFP

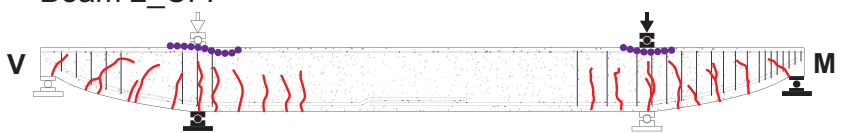

Beam 2 EC2

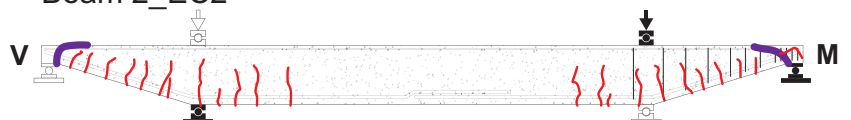
Beam 2_STM(i)

1 플 Beam 2_STM(ii)

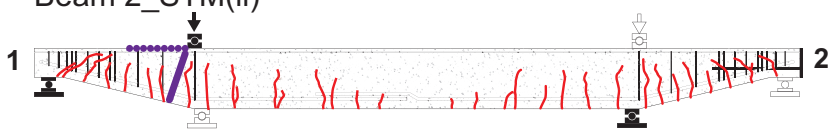
Beam 2_STM(iii)

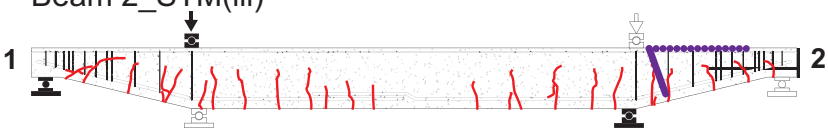

- Cracking

- Failure location

- Flexural Reinforcement

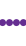

Figure 12: Summary of crack patterns at failure for all beams tested.
Beam 1_CFP_V

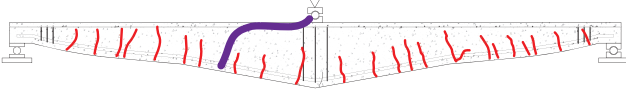

Beam 1_EC2_V

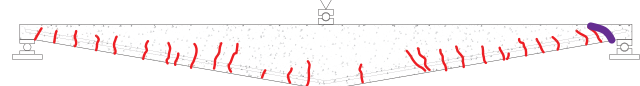

Beam 3_CFP_V/M

v

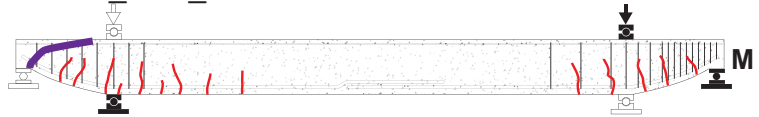

Beam 3_EC2_V/M

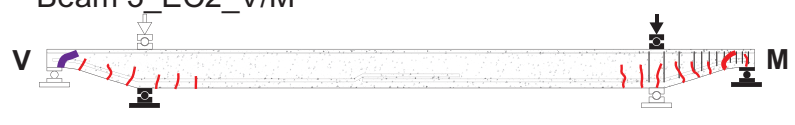

Beam 4_CFP_V/M

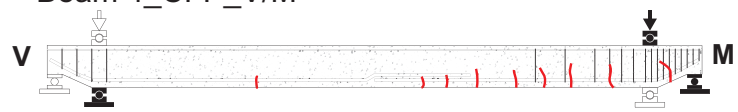

Beam 4_EC2_V/M

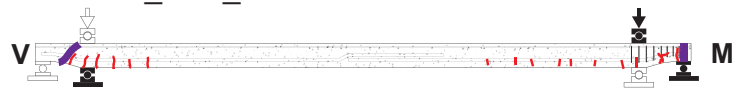




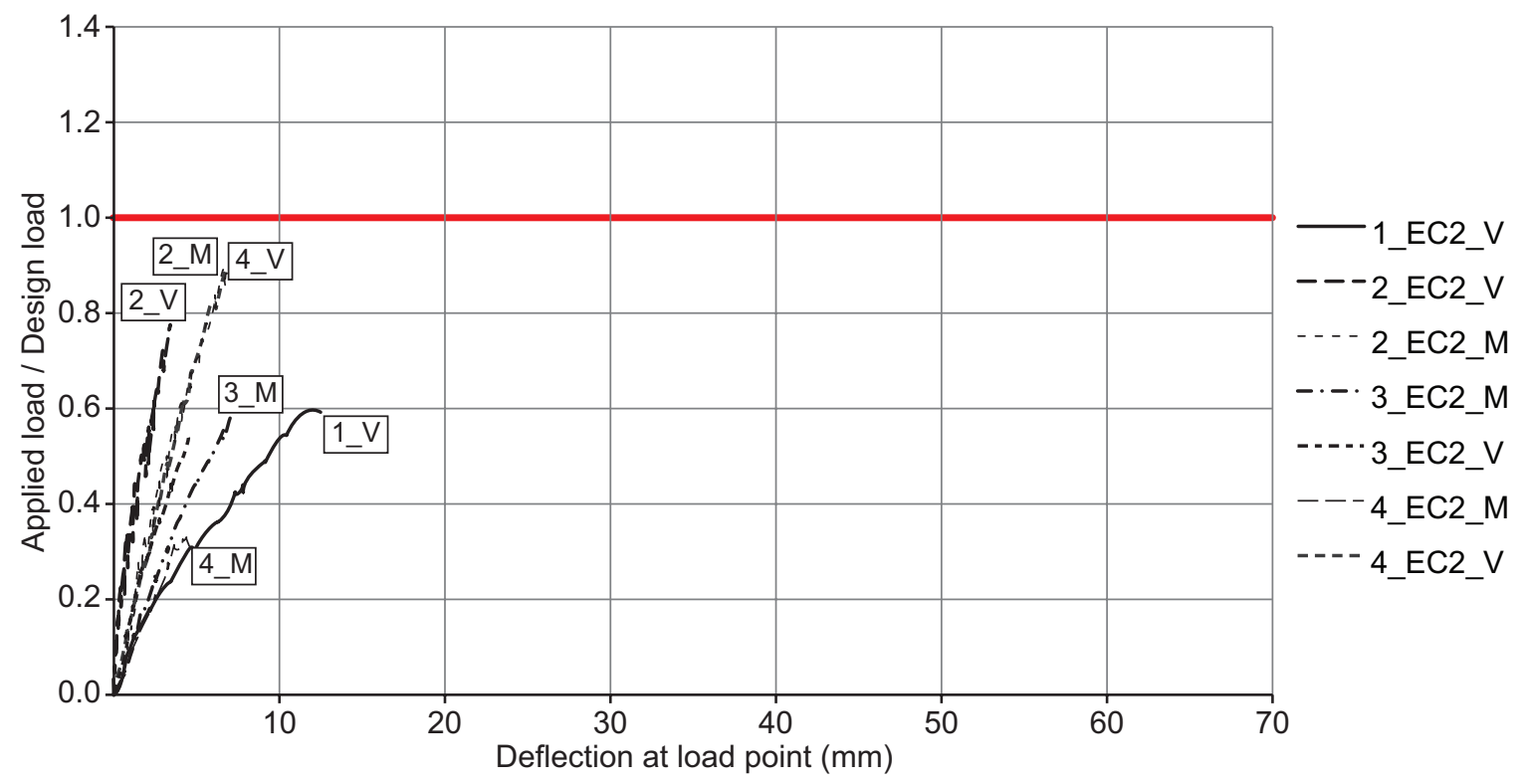

Figure 13: Normalised load-displacement results for EC2 beam series

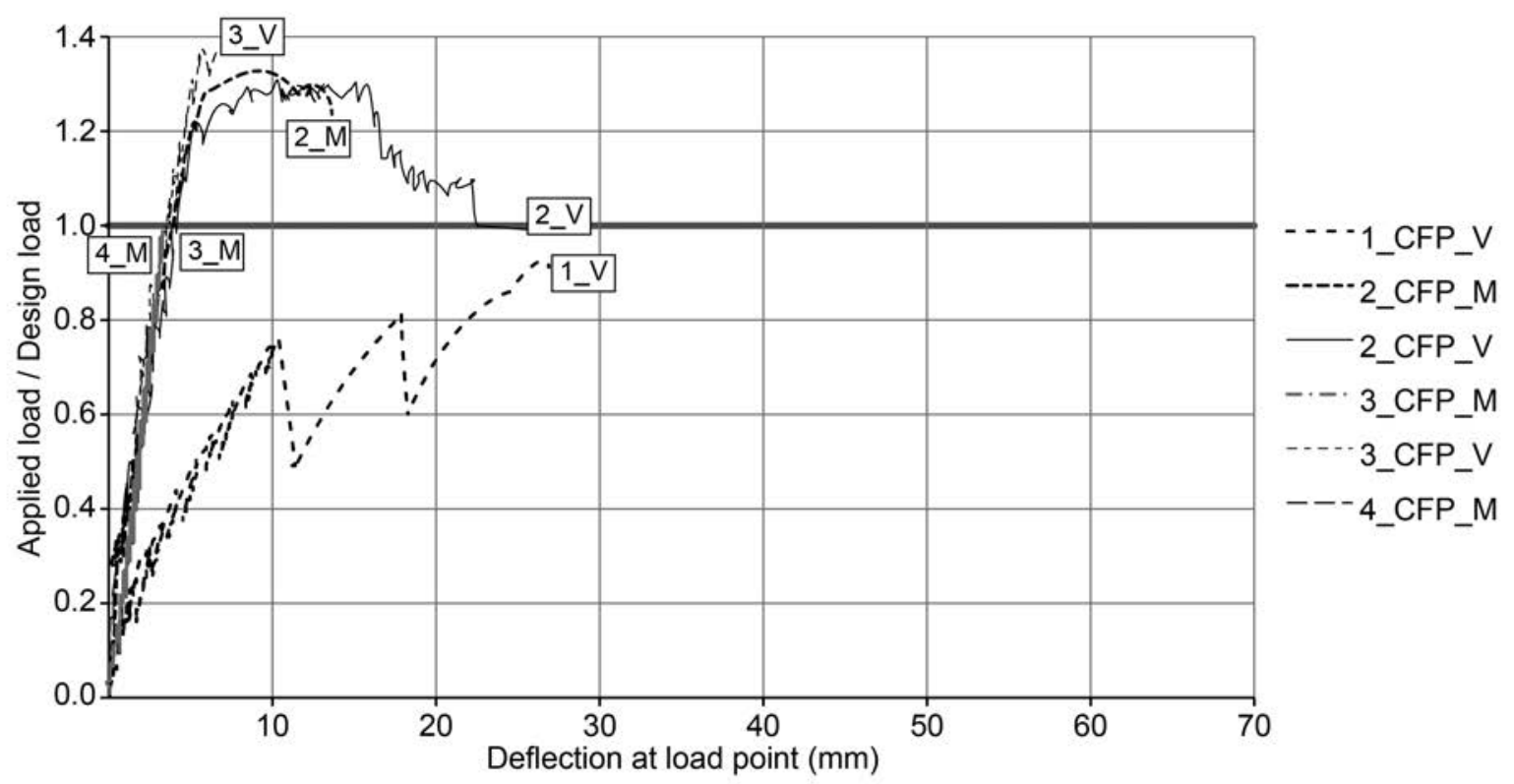

Figure 14: Normalised load-displacement results for CFP beam series 


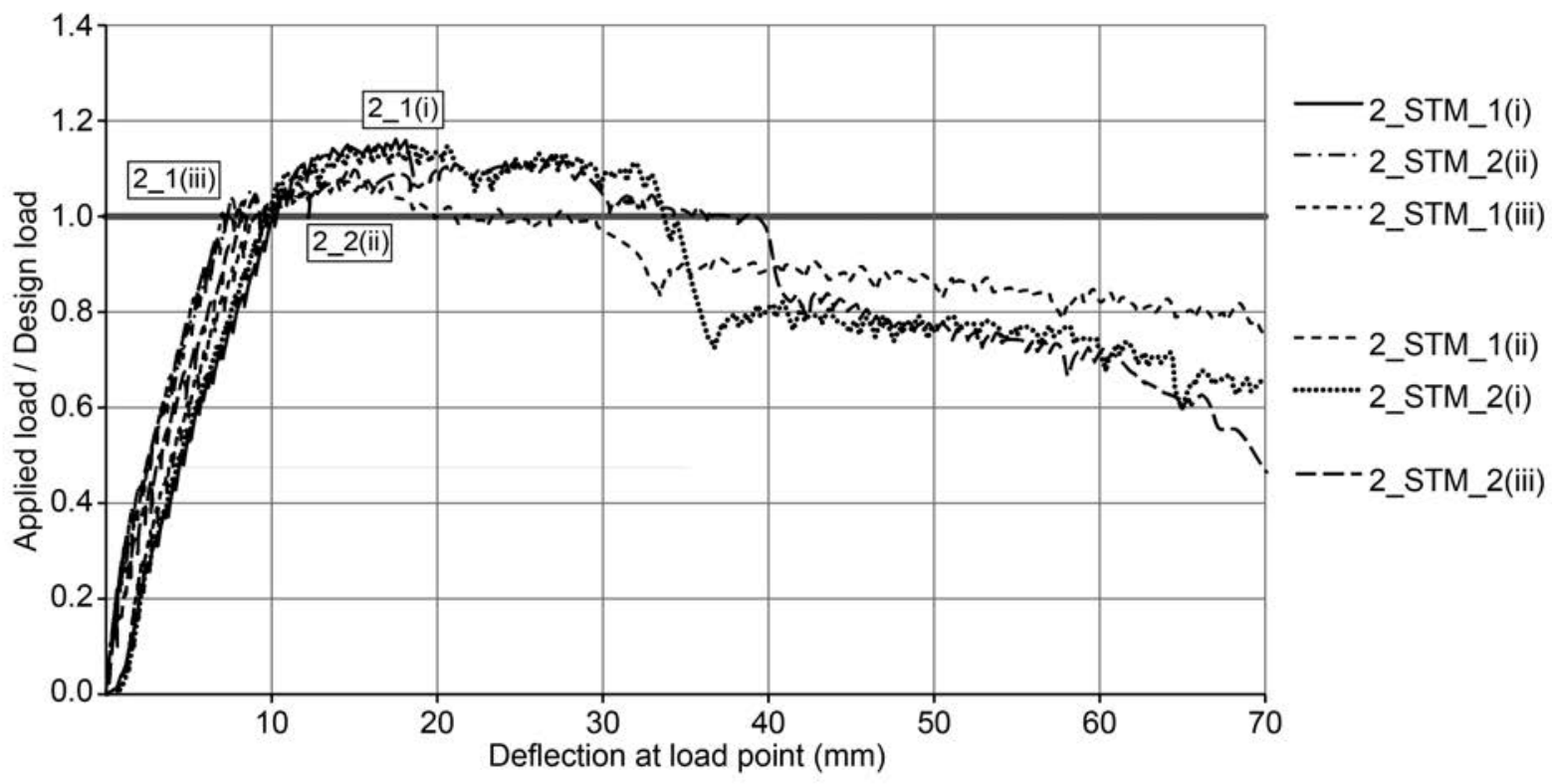

Figure 15: Normalised load-displacement results for STM beam series

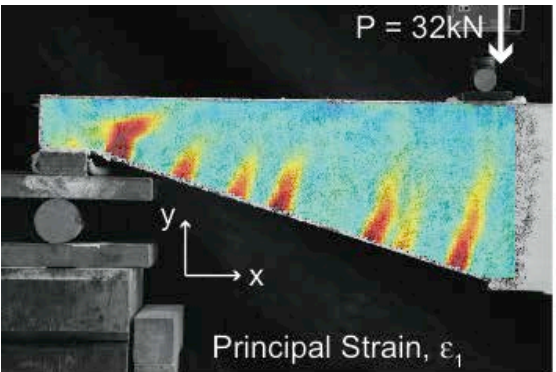

Beam 2_EC2_M at peak load

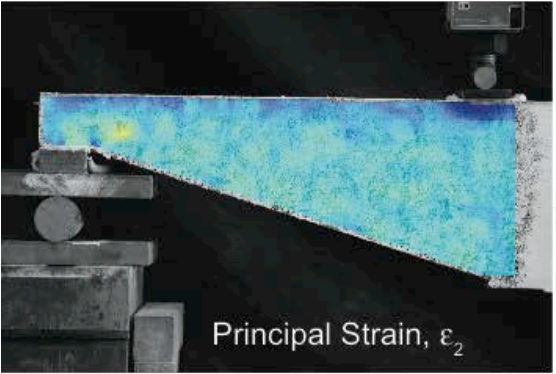

Reinforcement plotted in white

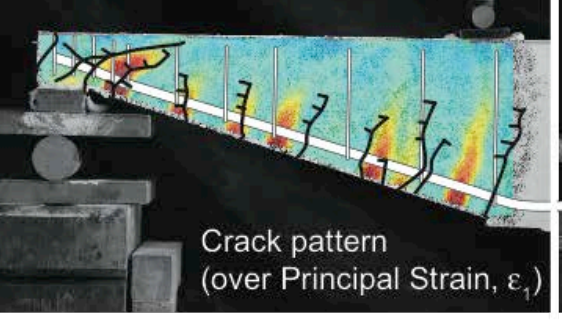

Contour

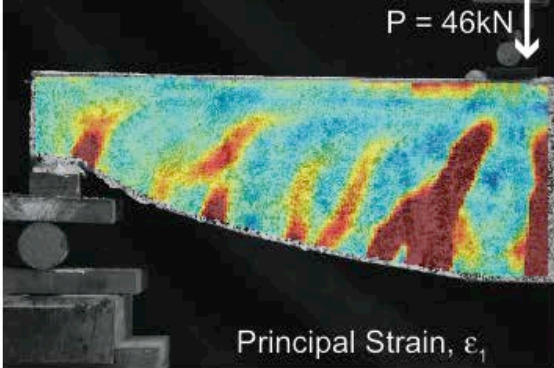

Beam 2 CFP M at peak load
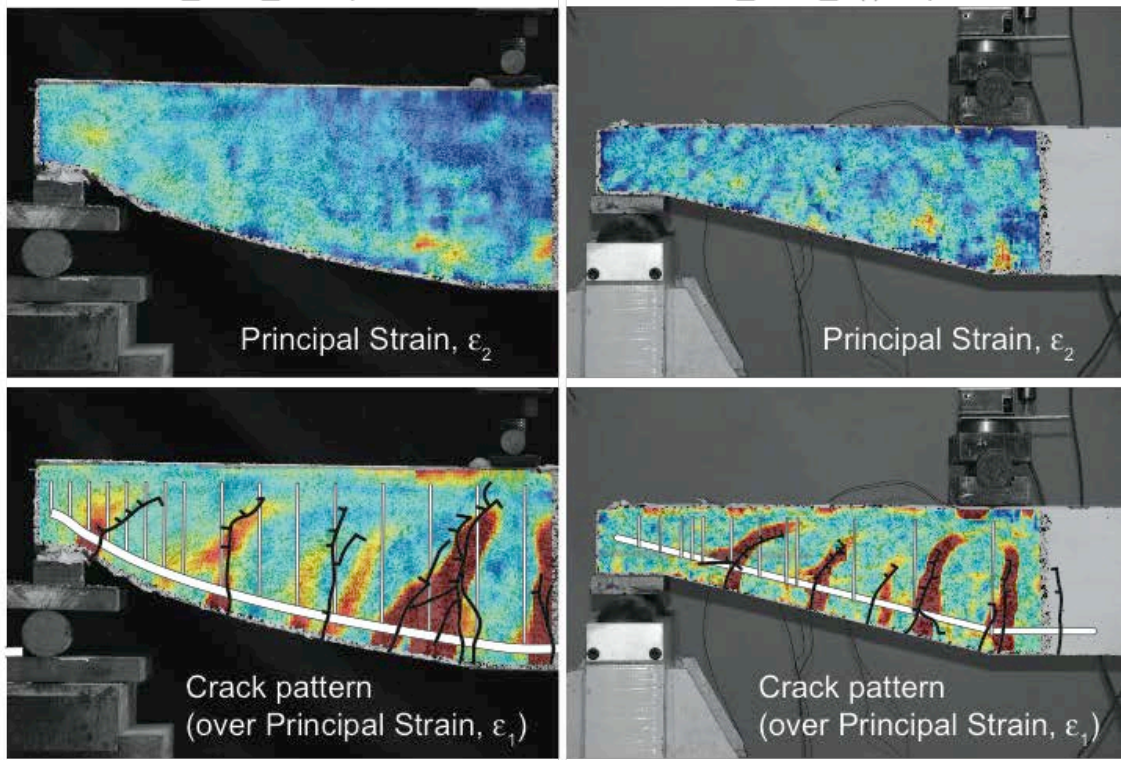

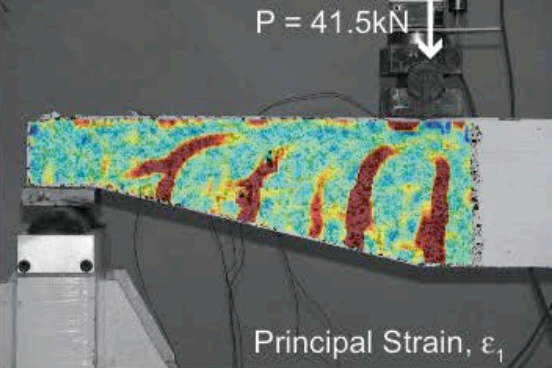

Beam 2_STM_2(i) at peak load

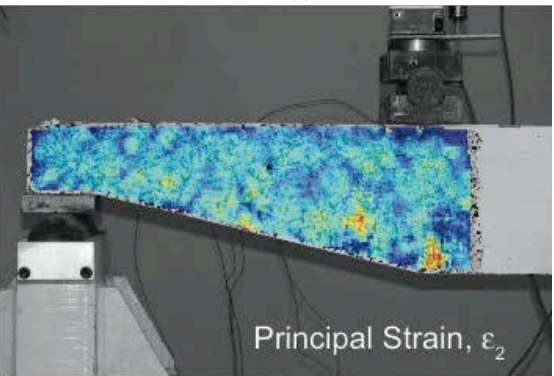

$1.0 \times 10^{-2}$

Figure 16: Strain plot comparison between EC2, STM and CFP beams at their respective peak loads. 


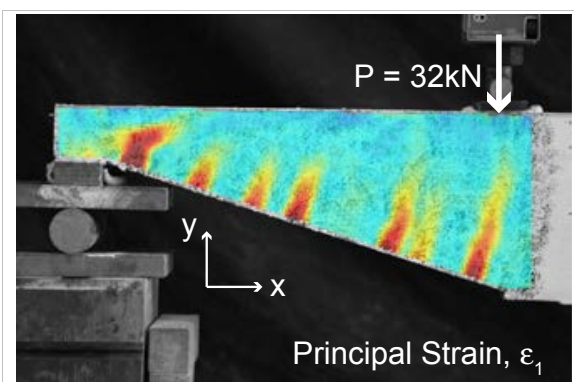

Beam 2_EC2_M at 32kN

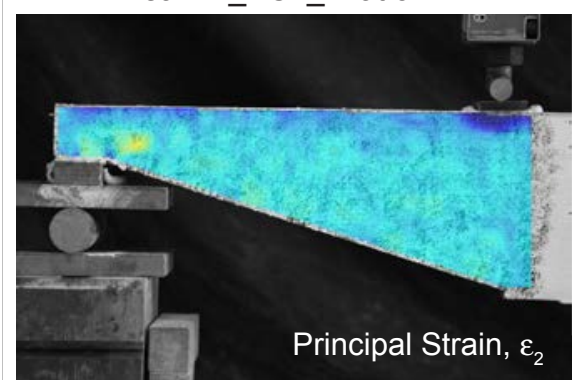

Principal Strain, $\varepsilon_{2}$

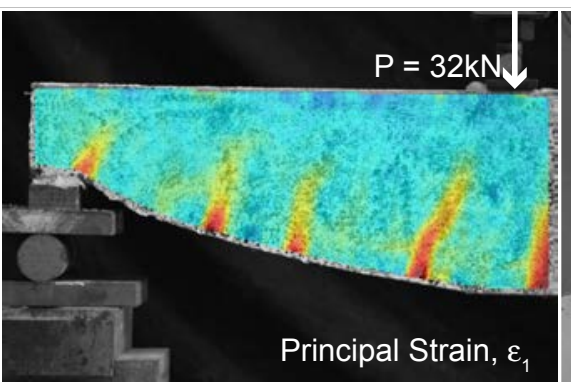

Beam 2_CFP_M at 32kN

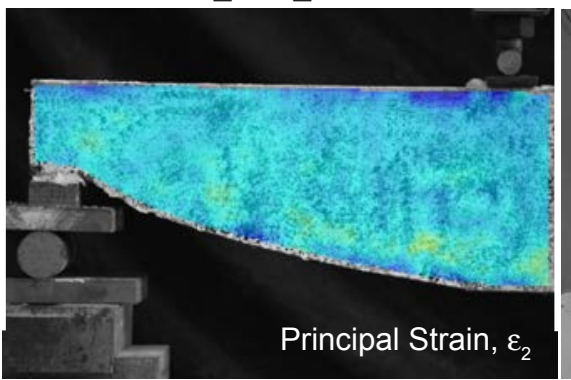

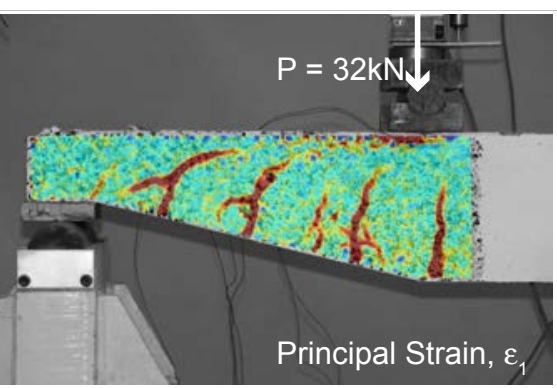

Beam 2_STM_2(i) at 32kN

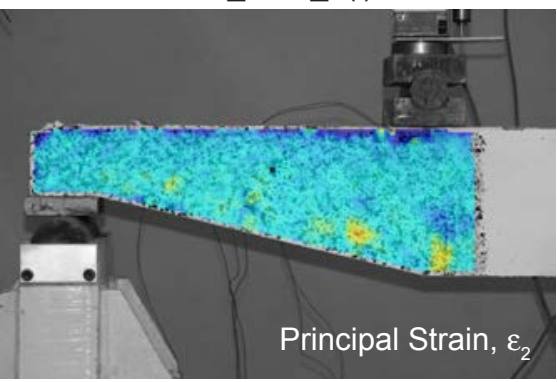

Principal Strain, $\varepsilon_{2}$

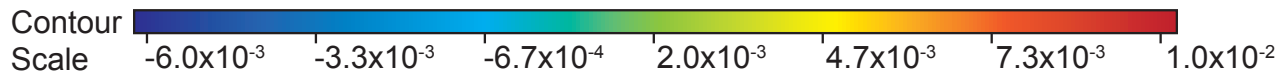

Figure 17: Strain plot comparison between EC2, CFP and STM beams at the failure load of Beam 2_EC2_M

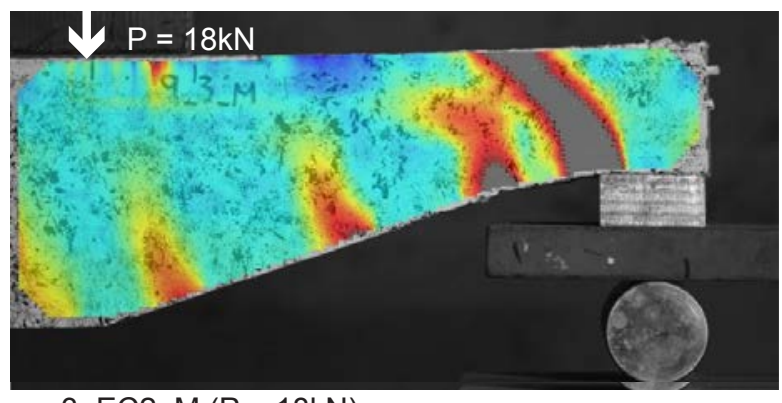

$\varepsilon_{1}: 3 \_E C 2 \_M(P=18 \mathrm{kN})$

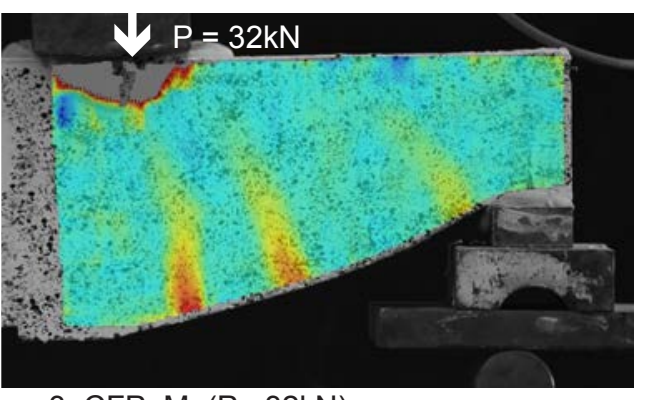

$\varepsilon_{1}:$ 3_CFP_M $(\mathrm{P}=32 \mathrm{kN})$

Figure 18: Comparison of principal strains in Beams 3_EC2_M and 3_CFP_M at their respective failure loads.

491

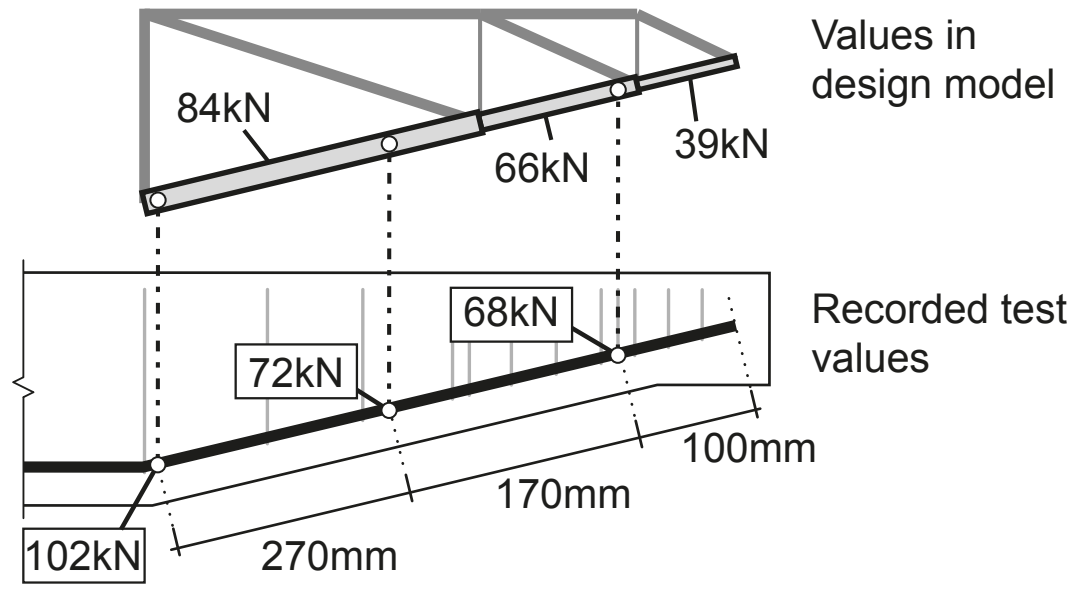

Figure 19: Forces derived from strain gauge readings compared to STM design model. 


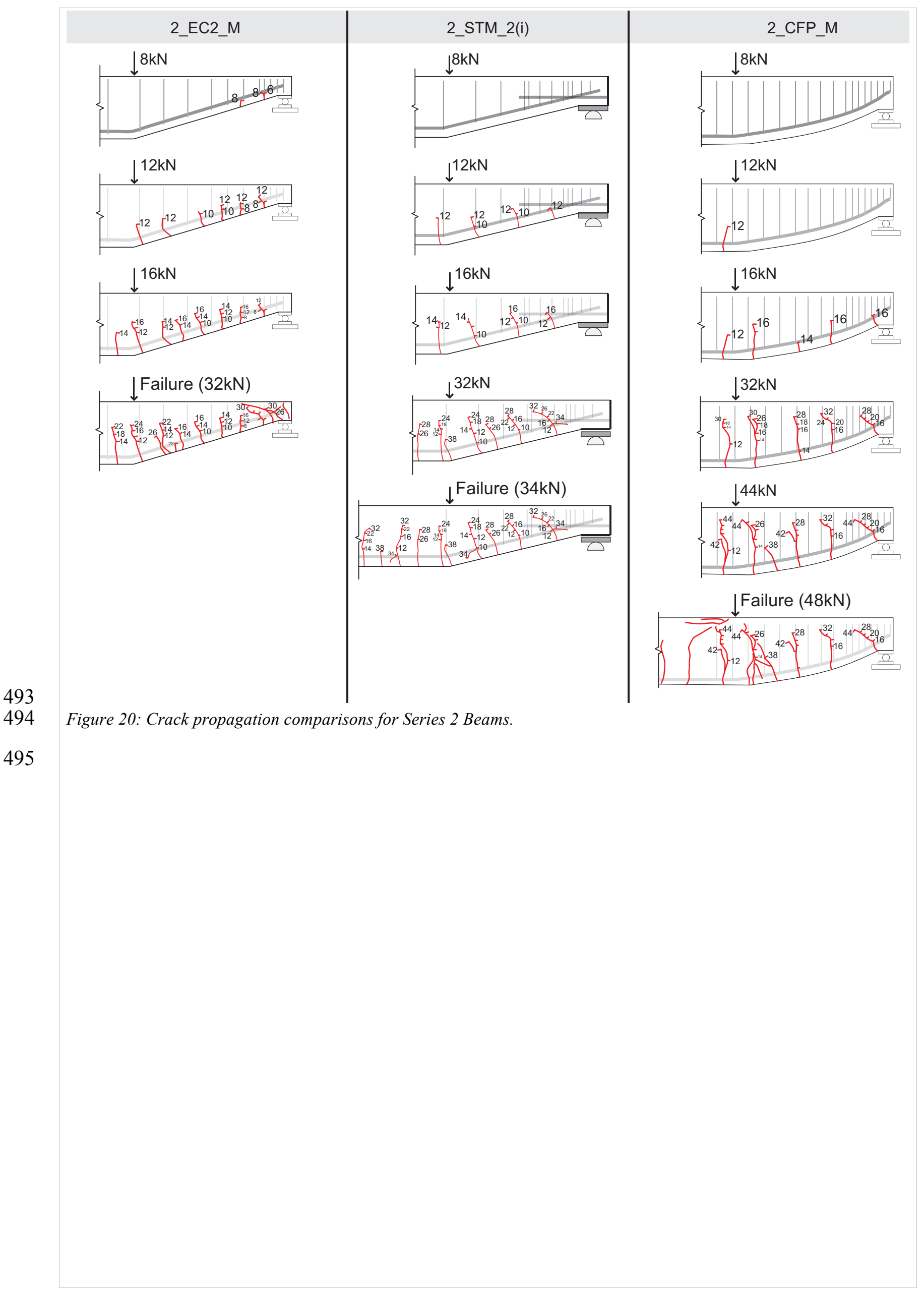

